\title{
An Investigation of Spoken Lexical Bundles in Interactive Academic Contexts
}

\author{
By \\ Daniel Sykes
}

\author{
A Thesis \\ Submitted to the Faculty of Graduate and Postdoctoral Affairs \\ In Partial Fulfillment of the Requirements \\ For the Degree of \\ Master of Arts
}

School of Linguistics and Language Studies

Carleton University
Ottawa, Ontario

(C) 2017

Daniel Sykes 


\begin{abstract}
This study investigates the presence of spoken four-word lexical bundles in university seminars, study groups and discussion groups in the humanities and social sciences. Transcripts of these speech events were gathered from the Michigan Corpus of Academic Spoken English (MICASE) and analyzed using corpus software. A list of lexical bundles was created, based on frequency and range criteria, and assigned functions according to Biber, Conrad and Cortes' (2004) taxonomy of lexical bundle functions. The most frequent of these bundles were further analyzed to determine their structural characteristics, with the goal of a creating a list of useful bundles for potential use in English for Academic Purposes teaching.
\end{abstract}




\section{Acknowledgements}

This research would not have been possible without the assistance of my supervisor, Dr. David Wood. It has been a pleasure to work under his support and guidance, and I sincerely appreciate having had the opportunity to work with him during my studies.

I would also like to thank the many fine members of the faculty at Carleton University from whom I have learned a great deal: Dr. Eva Kartchava, Dr. Trudy O’Brien, Dr. Michael Rodgers, Dr. Ann Laubstein, Dr. Jaffer Sheyholislami and Dr. Guillaume Gentil, and the kind and helpful support staff in the School of Linguistics and Language Studies.

Thanks also to my friends and colleagues with whom I have had the pleasure of working in the CTESL program as well as during my graduate studies. Their names are too many to list, but I remember and appreciate them all.

I also owe a great deal of gratitude to my family, who have stood behind me throughout my time at school. Without their support, I could not have accomplished my goals.

Finally, special thanks to my wife Naoko, who has always been there for me, and without whom I could not have succeeded. 


\section{List of Figures}

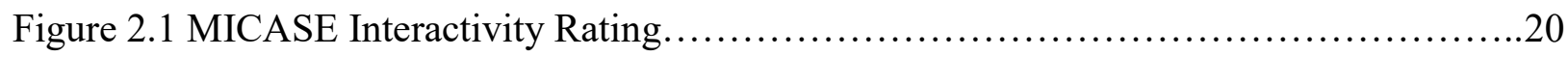

Figure 2.2 Description of transcripts used for the present study..........................23

Figure 2.3 MICASE transcripts token/type data.................................... 25

Figure 2.4 WordSmith Tools' Word List function, displaying four-word clusters..............29

Figure 2.5. Biber et al.'s (2004) taxonomy of functions of lexical bundles....................34

Figure 2.6 WordSmith Tools' Concordance function................................... 36

Figure 3.1 Lexical Bundles by type in MSIC Bundles List................................38

Figure 3.2 Top 30 frequent bundles in MSIC Bundles List.............................40

Figure 3.3 Structural types of lexical bundles.....................................43

Figure 3.4 Structural types of lexical bundles in the top 30 entries......................61

Figure 3.5 Structural sub-types of lexical bundles in the top 30 entries.....................63 


\section{Table of Contents}

\section{Table of Contents}

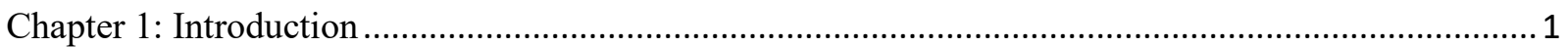

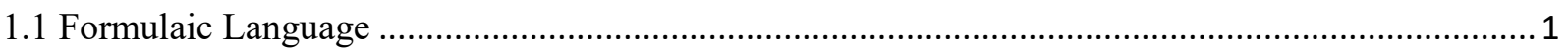

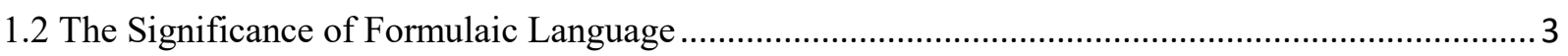

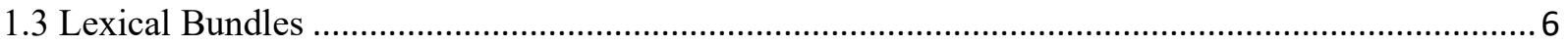

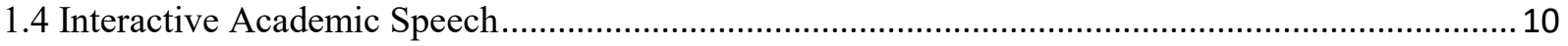

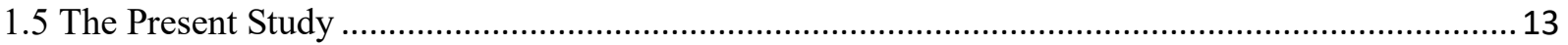

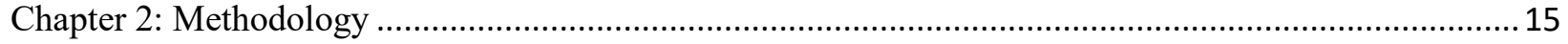

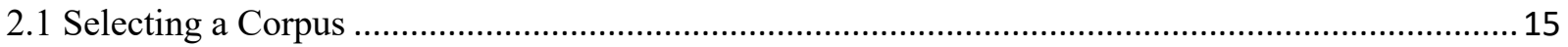

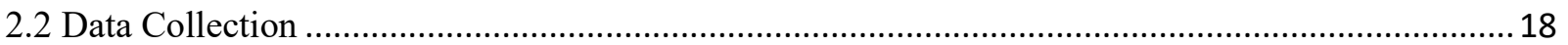

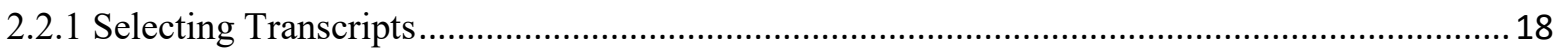

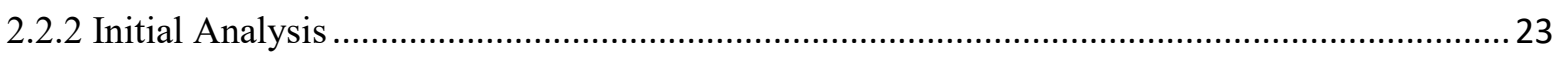

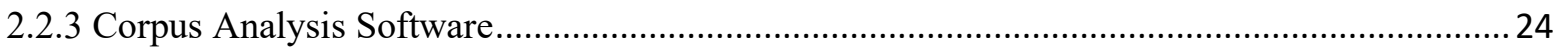

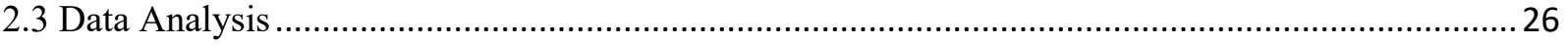

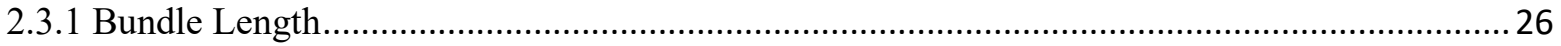

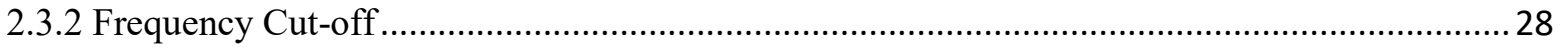

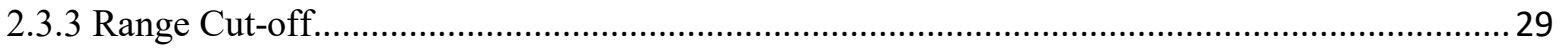

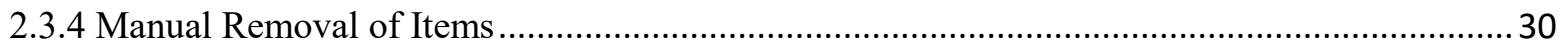

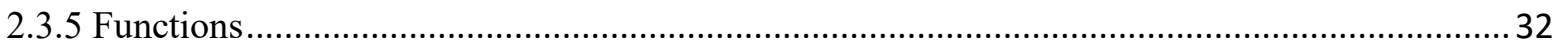

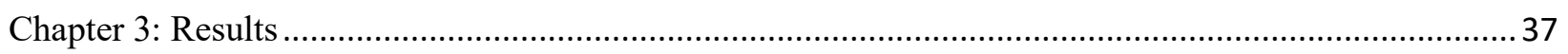

3.1 Overview of Frequent Bundles in the MICASE Spoken Interactive Corpus Bundles List ..............37

3.2 The Functions and Structural Characteristics of Bundles in the MSIC Bundles List.......................39

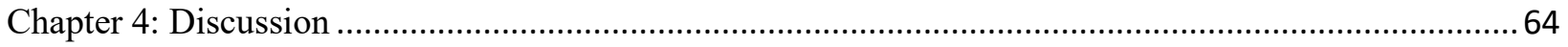

4.1 Potential Pedagogical Implications of the MSIC Bundles List.....................................................64

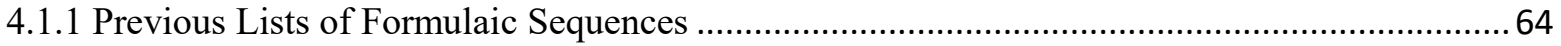

4.1.2 Teaching Lexical Bundles and other Formulaic Sequences.................................................67

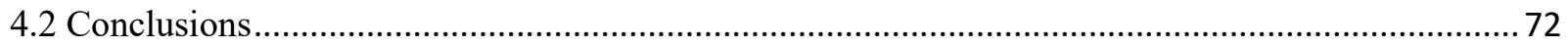

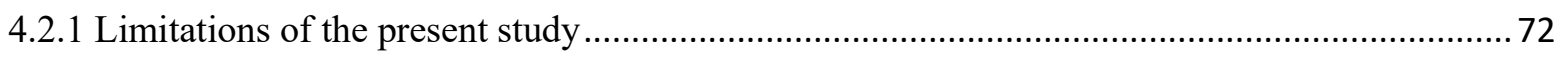

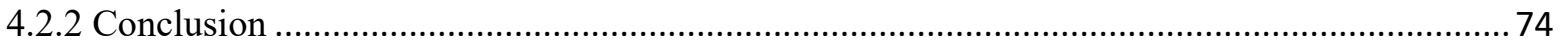

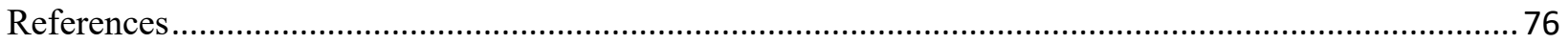

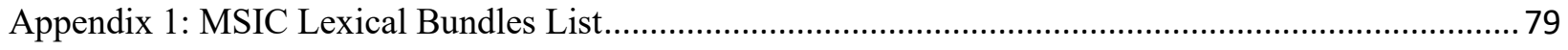




\section{Chapter 1: Introduction}

\subsection{Formulaic Language}

A key part of language learning and use is the ability to make use of formulaic language, prefabricated sequences of words, each consisting of a defined form, meaning and function. Ellis (2012) asserts that "the language system emerges from the statistical abstraction of patterns latent within and across form and function in language usage" (p. 17).

Through decades of research, these sequences have been assigned a wide variety of labels, such as "prefabs” (Bolinger, 1976), "lexicalized sentence stems” (Pawley \& Syder, 1983), “lexical phrases” (Nattinger \& DeCarrico, 1988, 1992), “lexical bundles” (Biber et. al., 1999), “chunks" (Boers \& Lindstromberg, 2009) and many others. They are perhaps most commonly referred to collectively as formulaic language, which Wray (2000) defines as follows:

A sequence, continuous or discontinuous, of words or other meaning elements, which is, or appears to be, prefabricated: that is, stored and retrieved whole from memory at the time of use, rather than being subject to generation or analysis by the language grammar. (p. 465)

These units of language have an important purpose in communication. Pawley and Syder (1983) state that there is, in most cases, more than one possible way of expressing an idea, but many of these ways do not sound natural to native speakers of a particular language. A nonnative speaker may be able to construct an utterance which is grammatically accurate, but which sounds awkward or unnatural to a native speaker. While in this case, the communicative purpose may have been carried out, the communication cannot be considered a complete success. Shin and Nation (2008) illustrate this concept with the following example:

... 'let me off here' can also be expressed as 'halt the car'. The latter sentence is strictly grammatical, but the problem is that native speakers do not say it in that way. This 
unnatural language use is problematical for learners in EFL contexts where the focus is on grammar. They may produce grammatically correct sentences, but many of them may not sound native-like. (p. 340)

These grammatical but unnatural utterances are a frequent problem in second language learning, as they have the potential to make communication more difficult for both speaker and listener. It is for this reason that having access to and knowledge of common sequences is important to second language learners. For a language learner, having a sizable repertoire of these items can allow for communication to be carried out more effectively, as they allow for the easy construction of discourse; Biber et al. refer to formulaic sequences as the "basic building blocks of discourse" (2004, p. 371).

The basic characteristics of formulaic sequences are as follows: first, they consist of multiple words; second, they carry a single meaning and/or function; and finally, they are prefabricated and/or stored and retrieved from memory as a single unit. (Wood, 2015). Obviously, the first two criteria are much easier to analyze than the third, or at least less subjective. Formulaic sequences exist at the boundary of syntax and lexicon; they carry both function and form, they are short and relatively fixed (Nattinger \& DeCarrico, 1992).

A great deal of research has been conducted on the importance of formulaic language in second language acquisition, and the results have shown that it has the potential to contribute to successful acquisition, production, fluency and pragmatic competence in language learners (Pawley \& Syder, 1983; Weinert, 1995; Myles et al., 1999; Wray, 2000; Wood, 2002; Wood, 2009; AlHassan \& Wood, 2015). As a result of this research it has become clear that second language learning materials ought to devote significant space to formulaic sequences if learners are to be provided with adequate exposure to this key aspect of language. 


\subsection{The Significance of Formulaic Language}

Research into use and functions of formulaic sequences in academic contexts has, to date, largely focused on written language. Less attention has been paid to how formulaic sequences are used in spoken academic language; in particular how they occur outside of classroom-based lectures. Despite the variety of non-classroom encounters occurring in academic environments, there has been little effort to investigate the degree to which formulaic sequences occur in these encounters, or the types of sequences most often used therein.

Formulaic language occurs frequently in everyday communication; it makes up much of our language use. Erman and Warren (2000) conducted a study which found that formulaic sequences accounted for $58.6 \%$ of spoken texts. Furthermore, the study's results suggested that these sequences may in fact be more common in spoken language than in written language (in the same study, formulaic sequences accounted for $52.6 \%$ of written texts) (Erman \& Warren, 2000). Altenberg (1998) investigated the London-Lund Corpus of Spoken English, a 500,000word corpus of spoken texts, and estimated that some $80 \%$ of the words found within formed some part of a formulaic sequence. From these studies it is clear that in ordinary conversation, formulaic sequences are a large part of language.

An area in which formulaic sequences play a key role in spoken language is that of pragmatics. Pragmatic competence, broadly defined as "the ability to communicate and interpret meaning in social interactions" (Taguchi, 2011, p. 289), is an important target for second language learners. Pragmatic competence can be divided into two areas: pragmalinguistics, the ability to use suitable language for defined functions, such as asking for directions, giving compliments, apologizing, and so forth; and sociopragmatics, a speaker's ability to comprehend the social context in which a given language function is carried out (Wood, 2015). Taguchi asserts that pragmatic competence requires "acquisition of both of these knowledge bases, as 
well as efficient control of them in real-time communication... pragmatics extends beyond grammar. It entails knowledge of forms, as well as their functional possibilities, and contextual requirements that determine form-function mappings" (2011, pp. 289-290). This reference to both form and function describes formulaic language perfectly. This is further illustrated by Bardovi-Harlig, who defines formulas in pragmatics as "recurrent strings or expressions used for specific pragmatic purposes... [which] capture the illocutionary force of a contribution by virtue of the fact that the speech community in which they are used has tacitly agreed on their form, meaning, and use" (2012, p. 207). In pragmatics, therefore, formulas are recurrent sequences of words whose meanings are generally agreed upon by a community of language users. Speakers who possess a repertoire of these sequences are more likely to be proficient in both pragmalinguistics and sociopragmatics than those who do not. It is for this reason that formulaic language can play a role in achieving pragmatic competence.

In academia, formulaic language is particularly significant - perhaps even more so in speech than in writing. Much of the previous research on formulaic sequences has occurred in the context of academic language. Biber, Conrad and Cortes (2002) investigated a corpus consisting of 4 million words of British English conversation and 3 million words of American English conversation, and found that lexical bundles accounted for approximately $28 \%$ of words in conversation, compared with $20 \%$ in academic writing.

Clearly, these sequences occur frequently in every type of speech. However, their frequency is not their only significance for language users. In academia in particular, formulaic sequences are important to speakers and writers for the following reasons, as outlined by Coxhead and Byrd (2007): 
a) the word sets are often repeated and become a part of the structural material used by advanced writers, making the students' task easier because they work with readymade sets of words rather than having to create each sentence word by word;

(b) as a result of their frequent use, such sets become defining markers of fluent writing and are important for the development of writing that fits the expectations of readers in academia;

(c) these sets of words often lie at the boundary between grammar and vocabulary; they are the lexicogrammatical underpinnings of a language so often revealed in corpus studies but much harder to see through analysis of individual texts or from a linguistic point of view that does not study language-in-use. That is, teachers and students may not be aware that these important sets of words exist, or that they exist as often repeated sets rather than as individual words and need to be learned and used as sets. (pp. 134-135).

While these explanations make frequent reference to writing, they also apply to speech. In particular, the first two points are extremely important. Formulaic sequences provide language learners with pre-made utterances which can easily be deployed in speech, and the prefabricated nature of these sequences can translate to improved fluency. The third point is also relevant; multi-word sequences, despite their ubiquity, may not be readily apparent to non-native speakers of a language. It is perhaps the nature of language learning to by default attempt to analyze a text or utterance by its component parts, on a word-by-word basis, rather than looking for frequent patterns. It is even less likely that they will consider the lexicogrammatical aspect of these sequences, even if they become aware of the patterns themselves, unless their attention is specifically directed to it.

Indeed, the challenges posed by formulaic language for second language learners are significant. Research indicates that formulaic sequences are not processed by learners in the same way as native speakers. Even when a second language learner successfully recognizes that a sequence is formulaic, the processing advantage gained by native speakers is either absent or 
occurs more slowly (Wood, 2015). The reason for this may simply be a lack of exposure; while a native speaker inevitably encounters even the most infrequent sequences throughout a lifetime of using a language, a second language learner may rarely or never be exposed to the less-common sequences (Ellis et al., 2008). Wood (2015) suggests that an additional challenge lies in the figurative meanings of some formulaic sequences; while native speakers are aware of their nonliteral meaning and will process them as such, second language learners need to "juggle literal and figurative options for a given sequence" (p. 140). If second language learners are to make meaningful use of formulaic sequences, these challenges must be overcome.

\subsection{Lexical Bundles}

Despite the broad consensus on the significance formulaic sequences have in language learning and use, there has been no consensus on what characteristics define them or what methodologies can be used to identify them (Biber, Conrad \& Cortes, 2003). The two key research issues involve the search for methods of identification and definition of multi-word sequences, and the ways to analyze the various functions that these units perform in discourse (Weinert, 1995).

Various proposals and frameworks for classifying multi-word sequences have been put forth. In order to search for and classify these sequences, various criteria are needed in order to determine what is a sequence and what is not. Altenberg (1998) used frequency - that is, the number of times a sequence appears within a given corpus - as a method of finding multi-word sequences, and also used the functions of these sequences in order to classify them. This would become one of the defining criteria of future lexical bundle research.

A particular type of sequence employing two criteria - frequency and function - often used in the study of formulaic language, particularly in academia, is the lexical bundle, defined by Biber and Barbieri as "simply the most frequently occurring sequences of words in a sub- 
corpus of texts from a single register, such as do you want to and I don't know what in conversation" (2007, p. 267). More than simply being frequent word strings, however, lexical bundles also carry out specific functions in discourse. They are typically identified using corpus analysis software, using criteria that will be described below. Conrad and Biber (2004) summarize the use of lexical bundles in formulaic sequence research as follows:

The purposes of the lexical bundle approach require that multi-word sequences be identified with priority given to frequency, fixedness, and sequences longer than two words. Our hypothesis is that extremely common, fixed sequences of words are used as unanalyzed chunks by speakers and writers, and therefore will have identifiable discourse functions in texts. (p. 58)

Biber et al. (1999) carried out an initial corpus-based study of lexical bundles which was ground-breaking in several ways: it was conducted from a register perspective and made a direct comparison between spoken and written registers; it empirically analyzed large corpora (5 million words per register); it relied entirely on frequency criteria to identify multi-word sequences; and it focused on longer sequences (4, 5 and 6 words in length) (Biber, Conrad \& Cortes, 2004).

In determining the frequency of lexical bundles in a text, a cut-off point is used; figures between 5 and 40 occurrences per million words are often cited in studies of lexical bundles (Biber et al., 2004). It is important to note that these cut-off points are often determined somewhat arbitrarily (Biber, 2006a). Decisions regarding frequency cut-offs are often based on previous studies or on the researcher's own intuitions. As such, there is no "correct" frequency cut-off to use in a study of lexical bundles. The first examination of lexical bundles (Biber et al., 1999) used a cut-off of 10 occurrences per million words. 
Lexical bundles must also be of a particular length. In general, lexical bundles are either three or four words long; two-word sequences are too numerous and five- and six-word sequences too uncommon to be of interest (Biber, Conrad \& Leech, 2002). Another key aspect in defining lexical bundles is their range - that is, the number of texts within which they appear in a given corpus. This measure is necessary in order to "guard against idiosyncratic uses by individual speakers or authors" (Biber et al., 2004). A sequence might appear very frequently in a corpus, yet might only be used by one or two speakers or authors, suggesting that it is not in fact commonly used. The appearance of a sequence in a wider range of texts written or spoken by multiple speakers or authors ensures that it is in fact a true lexical bundle.

Lexical bundles have other distinguishing characteristics. In most cases, they are not idiomatic in meaning; bundles such as when you talk about and at the same time are transparent in meaning from their component parts (Biber, 2006b). This contrasts with the more semantically opaque nature of idiomatic expressions, most of which, in fact, are not common enough to be classified as lexical bundles; expressions such as give me a break and drive me up the wall are "rarely attested in natural speech or writing" (Biber \& Barbieri, 2007, p. 270). It is therefore unlikely that an examination of frequently-occurring lexical bundles, whether in spoken or in written language, is likely to reveal many idiomatic expressions.

Another characteristic of lexical bundles is that they rarely compose a complete structural unit; a study by Biber et al. (1999, in Biber, 2006a) revealed that just 15\% of conversational lexical bundles represented complete phrases or clauses, while less than $5 \%$ of lexical bundles in academic prose could be described as complete structural units. In other words, the majority of lexical bundles are themselves incomplete and therefore usually bridge two structural units, beginning at a phrase or clause boundary, with the last words of the bundle representing the first 
element of a second structural unit (Biber, 2006b). This does not mean that any sequence of four words is valid, however. Only uninterrupted sequences of words are considered lexical bundles; any unit which crosses a turn boundary or a punctuation mark would be excluded (Biber et al., 2003). Despite being structurally incomplete and non-idiomatic, lexical bundles play a vital role in discourse: they serve as "a kind of pragmatic 'head' for larger phrases and clauses, where they function as discourse frames for the expression of new information" (Biber \& Barbieri, 2007, p. 270).

In attempting to ascertain the main discourse functions carried out by lexical bundles, Biber et al. (2004) created a functional taxonomy, based on university corpus data, which suggested three main categories: stance bundles, discourse organizers, and referential expressions, along with a fourth category, special conversation functions. They define these categories as follows:

Stance bundles express attitudes or assessments of certainty that frame some other proposition. Discourse organizers reflect relationships between prior and coming discourse. Referential bundles make direct reference to physical or abstract entities, or to the textual context itself, either to identify the entity or to single out some particular attribute of the entity as especially important. (Biber et al., 2004, p. 384)

Each of these categories is further divided into subcategories which describe more specific functions and meanings, further details of which will be discussed in the Methodology section.

Lexical bundles, therefore, can be summarized as follows: they are combinations of words that are three or more words in length, identified from a corpus using special software based on frequency and range criteria (Wood, 2015). They carry out specific functions for which a clear taxonomy exists, are generally non-idiomatic, and are often structurally incomplete. A 
discussion of one area in which lexical bundles may be particularly important will be discussed in the next section.

\subsection{Interactive Academic Speech}

As previously stated, a great deal of existing research into the use of lexical bundles and other formulaic sequences in academia has focused on written discourse. Furthermore, most studies which have focused on the spoken aspect of academic language have concerned themselves with lectures (Flowerdew, 1994). This may be a result of the availability of data (i.e., transcripts of lectures) or may be due to the assumption that lectures constitute the most important part of academic life for the student. Speech encounters like seminars, study groups and discussion groups, however, can be said to constitute a separate genre within academic speech, one that is significant to university students.

Despite the significance of this genre, only a few studies have looked at academic speech outside of lectures (Biber, 2006b). Furneaux et al. (1991) and Tracy (1997) looked at seminars and colloquia, while Swales (2001) investigated a number of different academic speech events in the then-incomplete MICASE Corpus, including seminars and study groups.

Few if any studies, however, have examined the use of lexical bundles in the genre. It is obvious to anyone who has attended academic lectures and seminars that the language used in these contexts is quite different. Study groups, for example, often include the negotiation and reconstruction of material from a course; participants often use narrative language to describe events that have previously occurred, while also using epistemic stance items to express different levels of uncertainty (Biber, 2006b). The need to carry out these functions seems tailor-made for certain lexical bundles - ones that might not necessarily occur in lectures. 
It is not only study groups, however, which suffer from a lack of investigation. Other, similar speech encounters, such as seminars and discussion groups, have received little investigation in terms of formulaic language, including lexical bundles. The primary characteristic which distinguishes these speech encounters from academic lectures is not the material being discussed; this should be similar if not identical to the topics found in lectures. It is chiefly in terms of interactivity that study groups and the like are unique.

Interactivity is concerned mainly with the length of the utterances of the speakers participating in a speech encounter. Obviously, academic lectures are not usually very interactive; they tend to consist of a professor or instructor speaking to students, possibly for hours, with very few interruptions. While some lectures are more interactive - they may include questions from the audience, or other speech from participants - in general, they can be considered monologic. This is perhaps more likely to be the case when there is a very large number of participants; university lectures in which the audience contains hundreds of people are extremely unlikely to have any meaningful amount of interactivity. However, even when there are fewer participants in a lecture, interactivity is not guaranteed. A lecture generally exists for one primary purpose: for the instructor to transmit information to the participants. This is in most cases a one-way process; while the students attending the lecture may make some small contributions to the transfer of information, the instructor is the main focus, and therefore his or her speaking turns are by far the longest and most frequent. Essentially, lectures are what Nattinger and DeCarrico (1992) call transactional discourse; the transaction occurring is one of information. Attendees of a lecture are not only rarely required to speak; it would be fair to say that they are rarely allowed to speak. In a lecture attended by dozens or hundreds of students, 
only a tiny fraction will ask a question. Attendees of an academic lecture typically listen in silence, interrupted perhaps by the occasional laugh or other non-linguistic exclamation.

Study groups and seminars, on the other hand, tend to be far more interactive than lectures. Participants are expected to contribute their ideas to the discussion and ask questions frequently. This is partly due to the number of participants; in many cases these events consist of a relatively small number of speakers. However, the main difference between these groups and academic lectures is that they are designed with student participation in mind; indeed, they are often intended to maximize student participation, whether or not an instructor is present (Simpson-Vlach \& Leicher, 2006). This means that speaking turns are shorter (i.e., they consist of fewer words, rather then simply being shorter in time elapsed), more turns are taken, and a greater number of attendees have opportunities to speak.

These differences in interactivity between academic lectures and study groups have implications beyond the length of turns. Nattinger and DeCarrico (1992) suggest that the formulaic sequences that occur in transactional discourse such as lectures are different from those occurring in more interactive speech encounters. Biber et al. $(2002,2004)$, in studies of lexical bundles in various academic contexts, found similar results. Their corpus data showed that lectures contained different functional and structural bundle types from study groups. If different formulaic sequences are used in interactive encounters, then materials based on the sequences found in academic lectures may not be helpful in preparing second language learners to take part in all the necessary speech events in an academic context.

In sum, interactive speech encounters in academia are a significant but little-investigated area of inquiry. These encounters have important differences from the usual academic lectures that university students encounter, and most likely have formulaic sequences which are unique to 
the genre. As university students often need to participate in these groups, it is important that second-language learners are aware of the language that is required to do so. Am examination of lexical bundles, their functions and their structural characteristics in this genre might shed some light on what is required of the participants, and could help to produce materials useful for academic learners of English as a second language.

\subsection{The Present Study}

The present study seeks to investigate a research gap: that of spoken lexical bundles within interactive academic contexts. As has been discussed above, lexical bundle research has largely focused on written contexts, and when it has addressed spoken language it has often been in the context of classroom lectures. In order to address this gap, the following research questions will be used:

1. Which lexical bundles occur most frequently in spoken language in university seminars, study groups and discussion groups in the humanities and social sciences?

2. What are the functions and structural characteristics of the most frequently occurring bundles in these contexts?

Corpus research was used to answer these questions, and to provide some insight into the language used in these contexts. Using corpus linguistics software, a corpus of academic interactive academic speech encounters was examined. The most frequently occurring lexical bundles were determined according to frequency and range criteria, and classified according to Biber et al.'s (2004) taxonomy of functions. Idiomatic or otherwise inappropriate bundles were then removed by hand, and a subset of the most frequent bundles was then examined in detail and classified according to function and structural characteristics. 
In order to answer these questions, this paper is organized into four sections. The first section introduces the topic, reviewing previous literature and key issues in formulaic language research. The second section describes in detail the methodology used to answer the two research questions, while the third section reports on the findings of this research. The final section discusses the potential implications of these findings before concluding with a summary of the research as a whole. 


\section{Chapter 2: Methodology}

Prior to discussing the methodology used in this study, we must first return to the research questions which guided my efforts:

1. Which lexical bundles occur most frequently in spoken language in university seminars, study groups and discussion groups in the humanities and social sciences?

2. What are the functions and structural characteristics of the most frequently occurring bundles in these contexts?

In order to answer these questions, I used a corpus-based approach to determine which lexical bundles occurred most frequently in a corpus of academic English. It was first necessary to identify a suitable corpus. A wide range of English-language corpora exist, covering different genres and registers. Some corpora focus entirely on written language, while others include a spoken component. Given that my research questions focus specifically on spoken bundles in academia, it was necessary to identify a corpus with a sizable spoken component. Predictably, corpora of spoken language are usually fewer in number and smaller in size than their written counterparts. This narrowed the search for candidate corpora significantly, but also ensured it would be more difficult to find an "ideal" corpus for this study.

\subsection{Selecting a Corpus}

The largest corpus of spoken language currently available is the Corpus of Contemporary American English (COCA), which includes a spoken language section of 109 million words. Most of COCA's spoken language component consists of transcripts of unscripted conversation from some 150 different American television and radio programs (ABC, CBS, NBC, Fox, PBS, NPR, etc.). This data is relatively recent, having been compiled between 1990 and 2015. While COCA was initially considered as a possible source of data for this study, it was ultimately rejected due to its focus on a non-academic genre. Another concern was that the 
participants in television and radio broadcasts would not be representative of the general population (and therefore might use different language, and consequently different lexical bundles). Despite its large size, COCA would not have been suitable for these reasons.

The British National Corpus (BNC) consists of some 100 million words, of which roughly $10 \%$ represent spoken data; this roughly 10 million-word subcorpus is further divided into two sections: recordings of spontaneous conversations and recordings of scripted events (Grant, 2005). For the purposes of this study, the latter sort of recording would not have been useful. As with COCA, the BNC spoken corpus is relatively recent; it includes no data older than 1991 (Grant, 2005).

The BNC was also considered for this study, but was ultimately rejected for two reasons. First, it did not appear that the academic component of the BNC would be sufficiently robust; few transcripts of interactive academic speech events appeared to be present. Second, the data consists entirely of British English and, therefore, is likely to contain lexical bundles different from those encountered in North American English. As a graduate student attending a North American university, and as a teacher of English as a second language in a North American context, I felt it was more appropriate for my own study and work context to focus on North American English. While there were likely examples of non-British speakers in the BNC, the corpus as a whole was likely to be representative of British English.

Also considered was the Corpus of Spoken Professional American English (CSPAE), a corpus of two million words divided roughly evenly between transcripts of White House press conferences and academic faculty committee meetings (Simpson, 2004). Ignoring the portion of the corpus devoted to press conferences (a more scripted and transactional form of communication than would be useful for this study), there remained one million words of 
spontaneous academic-focused speech. Ultimately, however, CSPAE was rejected due to the fact that the speech represented in the academic portion would not have adequately represented student talk - the participants would have been faculty members and the nature of the discussions would have led to different language being used.

Clearly, in order to conduct a study of academic spoken English, it was necessary to find a specialized corpus that focused mainly on the academic genre. The Michigan Corpus of Academic Spoken English (MICASE) was compiled by the University of Michigan's English Language Institute between 1997 and 2001, with transcription and proofreading being completed the following year; some 200 total hours of academic speech were recorded across the university (Simpson-Vlach \& Leicher, 2006). With a total of 152 speech events, MICASE contains examples of virtually every kind of speech event that occurs on a university campus - from academic lectures of varying sizes to lab sections to office hours and service encounters (Simpson-Vlach \& Leicher, 2006). The speakers include instructors, faculty and students of every level, both native and non-native speakers. The corpus consists of $88 \%$ native speakers and 12\% non-native speakers (Simpson, 2004). This wide variety of speakers and speech encounters, and the careful detail with which they were recorded and transcribed, offers many possibilities for research. Indeed, MICASE has been the primary source of data for a number of studies (see Swales, 2001; Poos \& Simpson, 2002; Nesi \& Basturkmen, 2006; Ellis et al., 2008; SimpsonVlach \& Ellis, 2010; Cheng, 2010).

MICASE is smaller than either the COCA or BNC corpora, with a comparatively modest total of 1.8 million words, but has major advantages over both: first, the data was compiled at an American university and therefore is much more representative of American English; and second, it is a corpus composed entirely of academic spoken English, and therefore provides the 
best possible "snapshot" of the language being used in a university context. The manner in which the corpus is organized and presented was also highly advantageous for research. MICASE was clearly the best available option to answer the research questions used in this study.

\subsection{Data Collection}

Having selected MICASE as my corpus of choice, it was then necessary to obtain the relevant data to perform the study. Data from the MICASE corpus is easily obtained, as the corpus is available online in its entirety, located at https://quod.lib.umich.edu/cgi/c/corpus/corpus?c=micase;page=simple. From this link, the corpus can be downloaded, or can be examined and searched. Detailed tools exist which allow users to search not only by type of speech encounter, but by academic discipline, gender and age of speakers and their native language. The careful organization of MICASE made the process of obtaining data extremely easy. Using the website tools, I was able to select and download the data used for this study: a total of fourteen transcripts of three different types of speech encounters - seminars, discussion sections and study groups - in the arts, humanities and social sciences at both the graduate and undergraduate level.

\subsubsection{Selecting Transcripts}

MICASE has four academic divisions: Physical Sciences and Engineering, Biological and Health Sciences, Humanities and Arts, and Social Sciences and Education (Simpson-Vlach \& Leicher, 2006). For the present study, only transcripts from the latter two academic divisions Humanities and Arts and Social Sciences and Education - were included. The decision to use data from the humanities and social sciences rather than from the hard sciences was mainly based on the availability of data. MICASE contains fewer examples of seminars, discussion groups and study groups in the hard sciences (in fact, there are no transcripts of seminars in any 
of the hard sciences in the corpus), and those discussion sections and study groups that are present in the corpus tend to have a lower interactivity rating than those in the humanities.

Using data from both the humanities and hard sciences would have created a larger corpus, but it seemed very likely that doing so would create further difficulties. Were this a comparative study, intended to find the differences between the lexical bundles used in separate academic disciplines, then using data from these two areas would have been appropriate. However, it seems very likely that the bundles employed most frequently in the humanities would be different from those found in the hard sciences. As a result, the final list might have been usable as a general solution for university learners of English, but it would have been less effective for students in the humanities or sciences than separate lists. A subsequent study could repeat the methodology of the present study, using MICASE transcripts of study groups and seminars in the hard sciences, and create a separate list of the most frequent lexical bundles in these disciplines. Having two separate lists not only offers opportunities for comparative research, but also ensures that the bundles found in each list are relevant to the learners' academic disciplines of choice.

Interactivity was an extremely important component of the data selection process for this study. In compiling the MICASE corpus, the researchers assigned an interactivity rating to each transcript. This rating is "based on the number of words per turn (WPT) throughout the whole transcript, regardless of how many speakers participate" (Simpson-Vlach \& Leicher, 2006, p. 34). The transcript is then placed in one of five categories, as per Figure 2.1. 


\begin{tabular}{|c|c|c|}
\hline Interactivity Rating & Code & Average WPT Range \\
\hline Highly Interactive & HI & $6-24$ \\
\hline Mostly Interactive & MI & $25-49$ \\
\hline Mixed & MX & $50-99$ \\
\hline Mostly Monologic & MM & $100-450$ \\
\hline Highly Monologic & HM & $500+$ \\
\hline
\end{tabular}

Figure 2.1: MICASE Interactivity Rating.

Unlike most lectures, which tend to be generally monologic in nature, study/discussion groups and seminars are usually much more interactive. To that end, only transcripts with an interactivity rating of "Mixed" or greater were selected for this study. Transcripts with this level of interactivity would more accurately represent the nature of seminars and study groups, in which discussions flow quickly and freely and in which speakers take shorter turns. Had more monologic encounters been included in the corpus, there would have been the risk of corrupting the frequency data by including lexical bundles particular to longer conversational turns such as in lectures, and therefore diminishing the utility of the list for participants in more interactive contexts.

The fourteen transcripts used for this study fell into three categories of speech event: seminars, study groups and discussion sections. The nature of these three speech encounters is described in some detail in the MICASE Handbook (Simpson-Vlach \& Leicher, 2006). This information will be summarized and presented in brief below.

The seminars used in this study consist of graduate level or upper-level undergraduate courses of three to 26 students, which typically meet once a week for three hours (SimpsonVlach \& Leicher, 2006). Students enrolled in these seminars engage in discussion of the course materials, taking relatively frequent turns with some longer stretches of speaking being present. 
Most of the seminars in the corpus are graduate-level or upper-year undergraduate level, with a few first-year level seminars also present (Simpson-Vlach \& Leicher, 2006). In general, these events consist of highly interactive discussion, with frequent, short speaking turns. The topics are unquestionably academic, although the speech ranges from highly conversational to much more academic in tone.

Study groups consist of meetings between three to six students working on exam preparation, homework or a final project; some of these groups have paid undergraduate peer leaders while others consist solely of current participants in their respective classes (SimpsonVlach \& Leicher, 2006). These groups are likely to be less formally structured than either seminars or discussion sections, with all participants contributing frequently to the discussion. Unlike discussion sections and seminars, in each of the transcripts of study groups used for this research all participants spoke. In a study group, turns are likely to be shorter than in either of the other two categories of speech event, simply because it is a highly informal encounter in which the participants are likely quite familiar and comfortable with one another, having already spent some time working together on a project or item of homework. These are perhaps the most "conversational" encounters in the corpus; an examination of the transcripts reveals that the speech found in these events appears most similar to ordinary conversation among universityaged individuals. The topics, however, are academic in nature. The participants discuss academic topics, ask each other questions, check for confirmation, and plan future actions.

The discussion sections are not courses themselves. Rather, they act as supplements to courses which consist of large lectures, and allow a smaller group of students (usually 20-30) an opportunity to engage with the course content in a more participatory manner; these sections are often led by a graduate student (Simpson-Vlach \& Leicher, 2006). As with seminars, there is 
some possibility that the content of these speech events may occasionally be monologic in nature, but the purpose is clearly for students to be able to participate freely and discuss the course content in a relatively interactive manner. These speech events are more structured than study groups, most likely as a result of having a designated leader. The graduate student leading the group guides the discussion, introducing topics, assisting with turn-taking and occasionally summarizing. These encounters bear some similarity to academic lectures, but are much more interactive.

All three types of speech events differ from traditional academic lectures in terms of number of participants and level of interactivity. As can be seen in Figure 2.2, all of the transcripts used in this study are participatory in nature, and are of a variety of lengths (both in elapsed time and in total words. Figure 2.2 also contains a sample of some of the pragmatic functions contained in each of the transcripts; this shows some of the variety of speech functions that are carried out in the different interactive contexts in academia.

The fourteen different speech encounters chosen for this corpus vary in terms of subject matter, from philosophy to politics, Buddhist studies to French cinema. The recordings varied in length from 51 to 169 minutes, for a total of approximately 24 hours of total speaking time. The number of speakers in each transcript ranged from 3 to 19 , though there were also non-speaking participants present in several of the speech encounters. The level of the participants varied. Some groups consisted solely of undergraduates, some solely of graduates, and one event was a mixed group. The MICASE Handbook includes a list of "pragmatic highlights" for each speech event: discussions, evaluations, questions, narratives, etc. (Simpson-Vlach \& Leicher, 2006, pp.101-252). 


\subsubsection{Initial Analysis}

After selecting and downloading the fourteen transcripts used for the study, the next step

involved a careful examination of the raw data. This was done electronically; each transcript was

opened using a text editor and carefully examined before a thorough "cleaning" process began.

This step was necessary due to MICASE transcripts containing a

\begin{tabular}{|c|c|c|c|c|c|c|c|c|}
\hline Transcript & $\begin{array}{l}\text { Acad. } \\
\text { Div. }\end{array}$ & $\begin{array}{l}\text { Interact. } \\
\text { Index }\end{array}$ & $\begin{array}{l}\text { Duration } \\
\text { (mins) }\end{array}$ & $\begin{array}{l}\text { Word } \\
\text { Count }\end{array}$ & $\begin{array}{c}\text { Participant } \\
\text { Level }\end{array}$ & Speakers & Participants & Pragmatic Highlights \\
\hline $\begin{array}{l}\text { History Review } \\
\text { Disc. Section }\end{array}$ & SS & MI & 119 & 15,679 & UG & 19 & 23 & $\begin{array}{l}\text { Examples, negative evaluation, positive evaluation, } \\
\text { questions, review for exam, sarcasm }\end{array}$ \\
\hline $\begin{array}{c}\text { Intro to } \\
\text { American } \\
\text { Politics Disc. } \\
\text { Section } \\
\end{array}$ & SS & $\mathrm{HI}$ & 55 & 7220 & UG & 18 & 25 & $\begin{array}{c}\text { Definitions, discussion, examples, humor, narratives, } \\
\text { questions, rhetorical questions }\end{array}$ \\
\hline $\begin{array}{c}\text { Intro to } \\
\text { Anthropology } \\
\text { Disc. Section }\end{array}$ & SS & MX & 51 & 7893 & UG & 17 & 23 & Examples, positive evaluation, questions \\
\hline $\begin{array}{l}\text { Philosophy Disc. } \\
\text { Section }\end{array}$ & HA & MI & 51 & 8355 & UG & 9 & 21 & Discussion, examples, positive evaluation, questions \\
\hline $\begin{array}{l}\text { American Family } \\
\text { Project Group }\end{array}$ & SS & $\mathrm{HI}$ & 85 & 13,388 & UG & 5 & 5 & Discussion, examples, narratives, tangents \\
\hline $\begin{array}{l}\text { Objectivism } \\
\text { Student Group }\end{array}$ & HA & $\mathrm{HI}$ & 125 & 20,830 & Mixed & 5 & 5 & $\begin{array}{l}\text { Advice/directions, definitions, disagreement, discussion, } \\
\text { examples, problem solving, questions }\end{array}$ \\
\hline $\begin{array}{l}\text { Undergrad Social } \\
\text { Science Thesis } \\
\text { Group }\end{array}$ & SS & HI & 64 & 14,000 & UG & 4 & 4 & $\begin{array}{c}\text { Advice/directions, negative evaluation, examples, humor, } \\
\text { narratives, requests, tangents }\end{array}$ \\
\hline $\begin{array}{c}\text { English } \\
\text { Composition } \\
\text { Seminar }\end{array}$ & HA & HI & 125 & 20,113 & UG & 11 & 12 & $\begin{array}{l}\text { Advice/directions, negative evaluation, positive evaluation, } \\
\text { examples, handout, humor, questions }\end{array}$ \\
\hline $\begin{array}{c}\text { First Year } \\
\text { Philosophy } \\
\text { Seminar }\end{array}$ & HA & $\mathrm{HI}$ & 72 & 10,300 & UG & 13 & 26 & $\begin{array}{l}\text { Discussion, negative evaluation, positive evaluation, } \\
\text { examples, questions, rhetorical questions }\end{array}$ \\
\hline $\begin{array}{c}\text { Graduate } \\
\text { Buddhist Studies } \\
\text { Seminar } \\
\end{array}$ & HA & MI & 167 & 21,537 & Grad & 8 & 9 & Definitions, questions \\
\hline $\begin{array}{l}\text { Graduate French } \\
\text { Cinema Seminar }\end{array}$ & HA & MI & 169 & 22,830 & Grad & 7 & 7 & Discussion, questions, tangents, visuals \\
\hline $\begin{array}{l}\text { Graduate Public } \\
\text { Policy Seminar }\end{array}$ & SS & MX & 143 & 24,180 & Grad & 11 & 15 & $\begin{array}{l}\text { Discussion, disagreement, positive evaluation, examples, } \\
\text { questions }\end{array}$ \\
\hline $\begin{array}{c}\text { Graduate } \\
\text { Philosophy } \\
\text { Seminar }\end{array}$ & HA & MI & 125 & 20,979 & Grad & 3 & 3 & Advice/directions, discussion, questions \\
\hline $\begin{array}{l}\text { Politics of } \\
\text { Higher } \\
\text { Education } \\
\text { Seminar }\end{array}$ & SS & MI & 108 & 18,687 & UG & 19 & 21 & Discussion, questions, humor, narratives, rhet. questions \\
\hline
\end{tabular}

Figure 2.2: Description of transcripts used for the present study (Simpson-Vlach \& Leicher, 2006).

great deal of metalanguage; nearly every sound and action that occurred during recording is reported in the transcript. This means that the raw transcripts contain a great deal of linguistically irrelevant annotations such as $<$ LAUGHS $>,<$ PAUSE $>,<$ COUGH $>,<$ WRITING ON BOARD $>$, $<$ ENTERING ROOM $>$, and so on. To ensure that the data could be reliably searched for lexical 
bundles using software tools, it was first necessary to remove all of these non-linguistic annotations, as well as various other metadata included in the transcripts in their original downloaded form. Had this metalanguage been allowed to remain in the transcript files, it is likely that the process of searching the transcripts with corpus tools would have been made more difficult, with irrelevant data and non-bundles appearing in the results.

\subsubsection{Corpus Analysis Software}

Having completed this process, each of the fourteen transcripts was loaded into

Wordsmiths Tools 7.0, a lexical analysis software program which has a number of features useful for corpus-based research. WordSmith Tools allows the user to create word lists from multiple text files, which was indispensable for this study. It also has a concordance function which is extremely useful for determining the manner in which a particular lexical bundle is used. The program is powerful and efficient, though it is somewhat less user-friendly than other alternatives (Ari, 2006). As a result, it was necessary to spend some time learning how to use the software correctly. WordSmith Tools allows the user to export his or her output to Microsoft Excel, and this was done throughout the research process, specifically with the index file and its statistics table. The resulting files were used for the examination of the data, as well as to create several of the tables and charts found in this paper.

The index file created from entering the fourteen edited transcripts totaled 227,308 tokens (words) consisting of 9720 types. The resulting type/token ratio (TTR) is 4.28 . TTR is a measure of linguistic richness or complexity derived by dividing the total number of tokens by the number of word types (Vermeer, 2000). Each individual transcript was more linguistically rich than the overall index; the repetition of word types across the fourteen texts results in the lower overall TTR. The individual transcripts ranged in length from 6,690 words to 24,455 words. 
Individual and overall analysis of the number of words (tokens) and types, as well as the TTR and mean word length can be found in Figure 2.2.

\begin{tabular}{|lllll|}
\hline Transcript & Tokens & Types & Type/token ratio (TTR) & Mean word length \\
\hline Overall & 227308 & 9720 & 4.28 & 4.15 \\
\hline MICASE Discussion 1.txt & 6690 & 1048 & 15.67 & 4.31 \\
\hline MICASE Discussion 2.txt & 7347 & 984 & 13.40 & 4.21 \\
\hline MICASE Discussion 3.txt & 7262 & 995 & 13.70 & 4.16 \\
\hline MICASE Discussion 4.txt & 14557 & 1966 & 13.51 & 4.11 \\
\hline MICASE Seminar 1.txt & 20722 & 1758 & 8.49 & 4.03 \\
\hline MICASE Seminar 2.txt & 24455 & 2794 & 11.43 & 4.34 \\
\hline MICASE Seminar 3.txt & 24263 & 2381 & 9.81 & 4.16 \\
\hline MICASE Seminar 4.txt & 22840 & 2717 & 11.90 & 4.00 \\
\hline MICASE Seminar 5.txt & 12941 & 1284 & 9.93 & 4.22 \\
\hline MICASE Seminar 6.txt & 19908 & 2253 & 11.32 & 4.20 \\
\hline MICASE Seminar 7.txt & 18652 & 1978 & 10.61 & 4.14 \\
\hline MICASE Study Group 1.txt & 20505 & 1661 & 8.10 & 10.53 \\
\hline MICASE Study Group 2.txt & 13192 & 1389 & 10.53 & 11.24 \\
\hline MICASE Study Group 3.txt & 13974 & 1571 & 169 \\
\hline
\end{tabular}

Figure 2.3. MICASE transcripts token/type data.

It is interesting to note the relatively short mean word length is consistent across all of the transcripts; this may well be the result of the less formal nature of interactive academic encounters as compared with academic lectures. While the topics being discussed in these events are indeed academic in nature, much of the language being used is shorter and less formal than that of lectures. Additionally, metalanguage such as stuttering and filled pauses, more frequent in 
interactive encounters due to the greater number of speakers, also contributes to the short mean word length. Other factors contributing to this include the pressure of speaking in a group, as well as the need to produce spontaneous utterances.

\subsection{Data Analysis}

After completing the initial analysis, the next step was to use WordSmith Tools to create a word list of all the transcripts combined. This function creates a list of every type of word and how many times it occurs in the corpus. Predictably, the most frequently occurring words by far were function words such as the, I, that, you, and, of and to. It is not until much later in the list that lexical words begin to appear.

While the word list is interesting, it is not in itself particularly relevant to the topic at hand. The next step was to use WordSmith Tools" "calculate clusters" function to search for multi-word strings. This function allows the user to select the cluster size (number of words) and minimum frequency, as well as to omit certain clusters such as those containing numbers, as well as - perhaps most importantly - phrase frames. By default, WordSmith Tools groups phrase frames together - that is, all clusters that are the same except for one word, which would be represented by a "wildcard" symbol, *. Therefore, clusters such as I don't know if, I don't know why and I don't know when would all appear as I don't know *. For the purposes of this study, it was necessary to omit phrase frames, as they would interfere with both frequency and range criteria.

\subsubsection{Bundle Length}

At this point in the research process, two key decisions had to be made: first, the size of "cluster" (i.e., lexical bundle) to search for, as well as the frequency cut-off. These were challenging decisions. Lexical bundles, as discussed in Chapter 1, can be of varying lengths. Bundles of four, five and six words are perhaps the most frequently investigated in research, 
while three-word bundles are a less frequent topic of examination. According to Appel, fourword bundles "seem to have become a standard unit of length in this type of research, [but] problems still persist" (2011, p. 69). The most significant of these problems has to do with the nature of the concordancing software programs used in this type of analysis; these programs often divide a five-word bundle into two overlapping four-word bundles (Appel, 2011). For example, the bundles at the end of and the end of the may overlap to form the five-word bundle at the end of the. In the present study, this problem has been addressed using human judgment; in cases where two bundles may overlap into a single longer bundle the concordances have been examined to determine how the bundle is being used in each individual occurrence. Where there is uncertainty, this has been noted in the results chapter.

For this study, a bundle size of four words was chosen. It was assumed that three-word sequences would be too frequent, and five- and six-word bundles too rare to create a useful list. Three-word bundles account for some $18 \%$ of words in conversation, while four-word bundles are just $2 \%$ (the balance consists of $79 \%$ non-recurrent sequences and $1 \%$ phrasal and prepositional verbs) (Biber et al., 2004). Five- and six-word bundles, therefore, must represent an extremely small portion of language use. In addition to this, Hyland (2008) argues that four-word bundles "offer a clearer range of structures and functions" than do three-word bundles (p. 8). The increase in length from three to four words allows these bundles to be more specific than their shorter counterparts; this allows for much easier identification of their functions.

Had the present study focused on five- and six-word bundles it seems unlikely that there would have been a great deal of pedagogical value in any resulting list; there would have been very few items of value. As will be seen in Chapter 3, many of the potential five-word bundles 
are questionable - it is not always clear if they are truly five-word items or simply four-word sequences with slots to be filled.

Further support for the use of four-word bundles comes from Cortes (2004), who found in a study of lexical bundles in student writing that many four-word bundles contain three-word bundles within themselves; as a result of, for example, contains the three-word bundle as a result (p. 401). From a pedagogical perspective, then, four-word bundles would seem to be a more efficient target structure than shorter bundles, as learners would naturally be exposed to shorter bundles through the learning of longer bundles.

\subsubsection{Frequency Cut-off}

The cut-off point was also a difficult choice. As stated in Chapter 1, cut-off points in studies of lexical bundles are often determined arbitrarily. After some consideration, it was decided that the frequency cut-off for the present study would be three occurrences in the corpus, equivalent to approximately 12 occurrences per million words. This falls well within the range established by previous studies; as previously stated, figures between five and 40 occurrences per million words have been used (Biber et al., 2004). A higher or lower cut-off point would naturally have resulted in a shorter or longer list, but it is unclear if there would have been any other significant implications. 


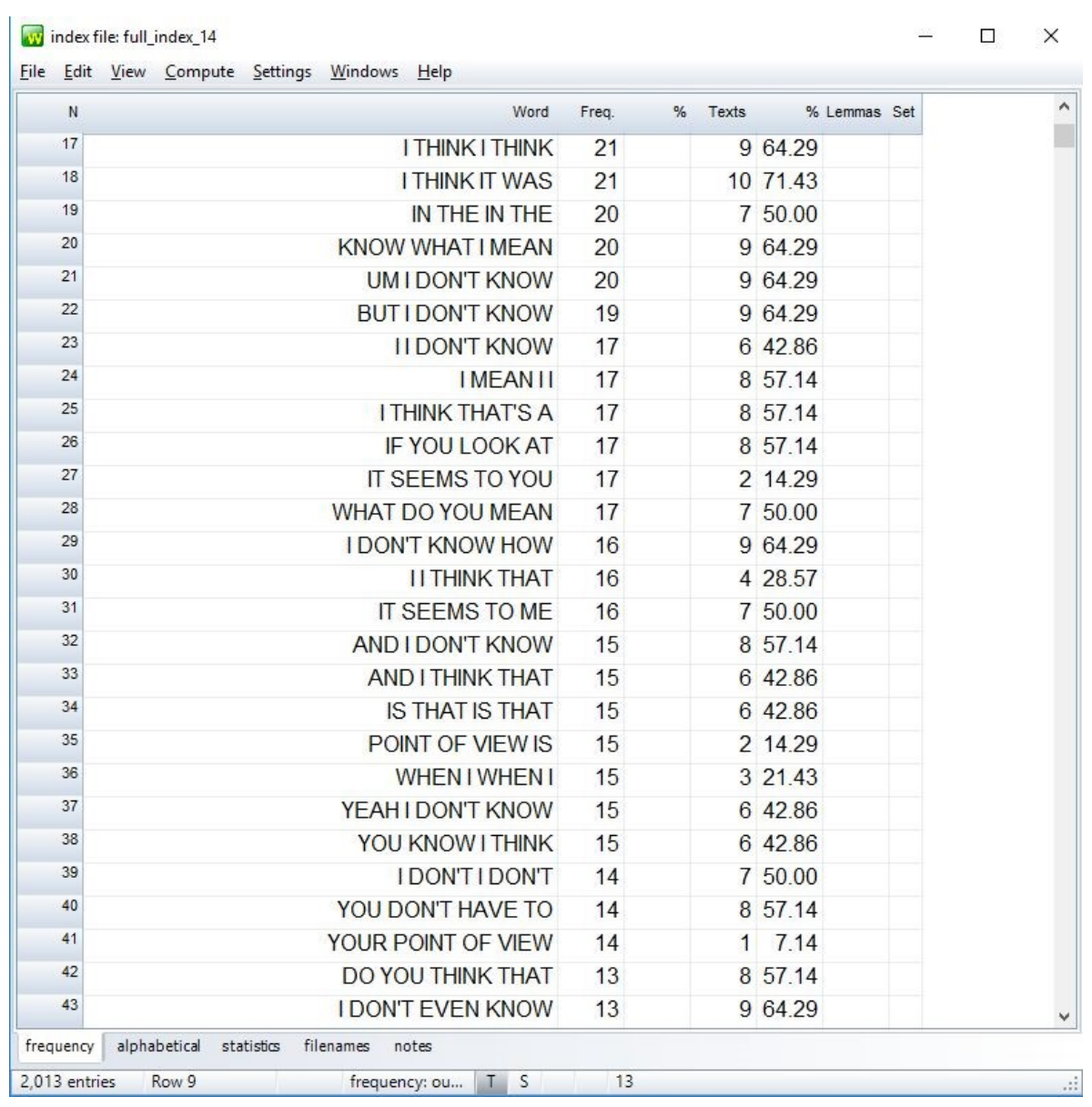

Figure 2.4 WordSmith Tools' Word List function, displaying four-word clusters.

\subsubsection{Range Cut-off}

This initial search for four-word clusters with a cut-off frequency of three occurrences yielded over 2,000 results. Clearly, this was far too large a number of clusters to create a useful list. It would not be possible to make use of such an enormous list in any pedagogical context; inevitably, an instructor would simply lop the most frequent items off the top of the list and ignore the rest. In order to reduce the number of items in the list, and to also protect against unsuitable items appearing, the next step was to apply range criteria. Range is another measure often used in studies of lexical bundles. Range requires that a bundle must appear in a certain number of different texts; this helps to "guard against idiosyncratic uses by individual speakers or authors" (Biber et al., 2004). Previous studies of this nature have used different range cut-offs; 
Biber et al. (2004), Cortes (2004, 2006), and Chen (2010) all previously used a cut-off of five texts. Hyland (2008) suggested a percentage-based approach, i.e. a sequence appearing in fewer than 10 percent of the texts would be eliminated. For this study, it was decided that a bundle should appear in at least three of the fourteen texts in the corpus (approximately $20 \%$ of the texts, in other words) in order to be included in the list. This would reduce (drastically) the number of total items in the list by eliminating those bundles which were peculiar to individual speakers. Even when using range criteria, however, it is far from guaranteed that idiosyncratic items will be eliminated entirely, as will be seen later.

\subsubsection{Manual Removal of Items}

After removing those items which did not meet the minimum range criteria, there remained a total of 916 clusters in the list. While this was still a very large number - still much too large to be useful for teaching - it was far more manageable than before the frequency and range criteria were applied. From this point, in order to further reduce the number of items in the list, it was necessary to examine each item manually to decide whether or not it should be included. This step in the process was unavoidable; it is not yet possible to remove human judgment from the process. Such subjective measures must be included in order to eliminate those items which frequency and range criteria alone could not. Examples of this will be discussed below.

It was immediately apparent that some items did not fit the characteristics of lexical bundles and therefore had no place in this list. For example, bundles that referred to specific people and/or organizations, such as $L S$ and $A$ and The University of Michigan were removed because, despite their frequency in this particular corpus, they could not be considered to occur frequently in general conversation, nor did they carry any functions. Items such as these are the very definition of idiosyncratic; they occur solely as a result of the location at which the speech 
events took place. Other bundles that were removed included those that were less clearly idiosyncratic, but with which it was still readily apparent that they are not in frequent use. Examples include eyes of the poor, on the sea floor, the center of gravity and procedure includes declaring witnessing. All of these items were able to evade the frequency and range criteria, despite the fact that they are idiosyncratic; clearly, they are not at all common in academic discussion outside of a specific context or field. Additionally, few of these items had any function according to the taxonomy used by Biber et al. (2004). The presence of these bundles indicates that frequency and range criteria alone are not always sufficient protection against the idiosyncrasies of individual speakers, and that a human eye is still needed in order to weed out those items that slip through the established criteria.

Still more items were neither overly specific nor idiosyncratic, but were still unsuitable for a list which would be used in an educational context. There were a large number of "bundles" present that consisted of stuttering and/or repetition of words for non-linguistic reasons. Clusters such as uh uh I I or um you know um represent filled pauses rather than actual meaning. A surprisingly large number of these clusters were present in the initial list and needed to be removed. Obviously, these items have little value to second language learners; they do not represent any lexical meaning. While they do have one function - holding one's turn, preventing it from passing to the next speaker - these items do not need to be taught in a second language context. Filled pauses are not unique to English, and while the specific sounds used to fill a pause may differ from one language to the next (Japanese speakers, for example, will say eto rather than $u m$ or $u h$ ) it is not necessary - and perhaps not possible - to teach a language learner how to fill a pause. 
After removing the aforementioned clusters, some 750 items remained on the list. This number, while far more manageable than the 2,000 entries which had initially been present, was still far too large to create a list of spoken lexical bundles which might be of any use in a pedagogical context. The final step in the process of creating such a list, therefore, was removing those clusters which, while neither idiosyncratic nor metalinguistic in nature, were in some other manner incomplete or unsuitable.

This step presented unique challenges. The previous steps had generally allowed the use of specific criteria with which to determine a bundle's suitability. At this point, however, it was necessary to rely almost entirely on intuition as both a native speaker of English and as an applied linguist. As a result, this was also the step in which the most risk was taken. For each bundle, it was necessary to determine whether or not there would be value in a university-level learner of English as a second language to be explicitly instructed in its use. This process pared the list down substantially. The final list of spoken lexical bundles contains 183 entries, all of which meet criteria of frequency, range and functional utility, and all of which should be useful in seminars and study groups at the university level.

\subsubsection{Functions}

Having completed the list, the research process was not yet finished. In order to address my second research question, it was necessary to determine the function of each of the 183 bundles in the list. Due to the variety of items present, it was determined that using a clear and well-established taxonomy of lexical bundles would be the simplest and most effective way of classifying their functions.

Biber, Conrad and Cortes (2003) created an initial taxonomy of the discourse functions of lexical bundles, in which they established four categories: referential bundles, text organizers, 
stance bundles and interactional bundles. After further research this taxonomy was revised and three categories were used: stance expressions, discourse organizers and referential expressions: Stance bundles express attitudes or assessments of certainty that frame some other proposition. Discourse organizers reflect relationships between prior and coming discourse. Referential bundles make direct reference to physical or abstract entities, or to the textual context itself, either to identify the entity or to single out some particular attribute of the entity as especially important. (Biber et al., 2004, p. 384)

A fourth category, special conversational functions, also exists; this is divided into expressions of politeness such as thank you very much, simple inquiry bundles such as what are you doing, and reporting bundles such as I said to her (Biber et al., 2004, p. 388). However, none of these items were present in the list of bundles derived from the MICASE corpus.

Using Biber et al.'s taxonomy, each of the 183 items in the list was assigned to one of the three categories. This was not particularly time-consuming but it did require some use of intuition. Descriptions of Biber et al.'s functional taxonomy often include examples, but naturally these examples do not include all possible bundles that might be part of a certain category. Where possible, examples from Biber et al.'s (2003) study were used to guide my attempts to classify bundles into the correct categories.

The next step was to place each bundle into a subcategory. Biber et al.'s (2004) taxonomy included several specific subcategories used for certain functions and meanings. A full list of these categories can be found in Figure 2.4 below. 


\begin{tabular}{|c|c|c|}
\hline Category & Subcategory & Examples \\
\hline Stance expressions & $\begin{array}{l}\text { Epistemic stance } \\
\text { - Personal } \\
\text { - Impersonal } \\
\text { Attitudinal/modality stance } \\
\text { - Desire } \\
\circ \quad \text { Personal } \\
\text { - Obligation/directive } \\
\circ \quad \text { Personal } \\
\circ \quad \text { Impersonal } \\
\text { - Intention/prediction } \\
\circ \quad \text { Personal } \\
\circ \quad \text { Impersonal } \\
\text { - Ability } \\
\circ \quad \text { Personal } \\
\circ \quad \text { Impersonal }\end{array}$ & $\begin{array}{l}\text { I don't know if } \\
\text { are more likely to } \\
\text { if you want to } \\
\text { you don't have to } \\
\text { it is necessary to } \\
\text { I'm not going to } \\
\text { it's going to be } \\
\text { to be able to } \\
\text { can be used to }\end{array}$ \\
\hline Discourse organizers & $\begin{array}{l}\text { - Topic introduction/focus } \\
\text { - Topic elaboration/clarification }\end{array}$ & $\begin{array}{l}\text { what do you think } \\
\text { has to do with }\end{array}$ \\
\hline Referential expressions & $\begin{array}{l}\text { - Identification/focus } \\
\text { - Imprecision } \\
\text { - Specification of attributes } \\
\circ \quad \text { Quantity } \\
\circ \quad \text { Tangible framing attributes } \\
\circ \quad \text { Intangible framing attributes } \\
\text { - Time/place/text reference } \\
\circ \quad \text { Place reference } \\
\circ \quad \text { Time reference } \\
\circ \quad \text { Text deixis } \\
\circ \quad \text { Multi-functional reference }\end{array}$ & $\begin{array}{l}\text { that's one of the } \\
\text { or something like that } \\
\text { there's a lot of } \\
\text { the size of the } \\
\text { in the case of } \\
\text { in the United States } \\
\text { at the same time } \\
\text { as shown in figure } \\
\text { the end of the }\end{array}$ \\
\hline
\end{tabular}

Figure 2.5. Biber et al. 's (2004) taxonomy of functions of lexical bundles.

In assigning each of the 183 items to a subcategory, it was in many cases once again necessary to use judgment and intuition, based on the individual concordances of each bundle, to determine in which category a bundle should be placed. This part of the process also resulted in 
many of the initial category assignments being changed, as bundles that had initially appeared to be of one type were reassigned to a different category. Many bundles that seemed at first to be stance bundles were in fact discourse organizers. After completing the process of assigning the bundles to sub-categories, there was less doubt about the proper function of each. Looking at the concordances of each bundle provided valuable information about the way in which it was used in actual speech. As each bundle appeared several times in the corpus, there were usually sufficient examples to determine which category and subcategory were most suitable.

The next step in attempting to answer the research questions of this study involved using WordSmith Tools' Concord function. In order to ensure the accuracy of my previous attempts to determine the pragmatic functions of the lexical bundles found in MICASE, I first created a text file including all 183 lexical bundles found in the final version of the list. I then used the Concord function to search the entirety of the original subcorpus - all fourteen texts, totaling 227,308 words - for examples of the individual bundles in the contexts they were used. The result was a concordance list, over 1,100 lines in length. Using this list, it was possible to search for any individual bundle in the list and see the context in which it was used. In Figure 2.5 below, several bundles are shown in their original contexts. 


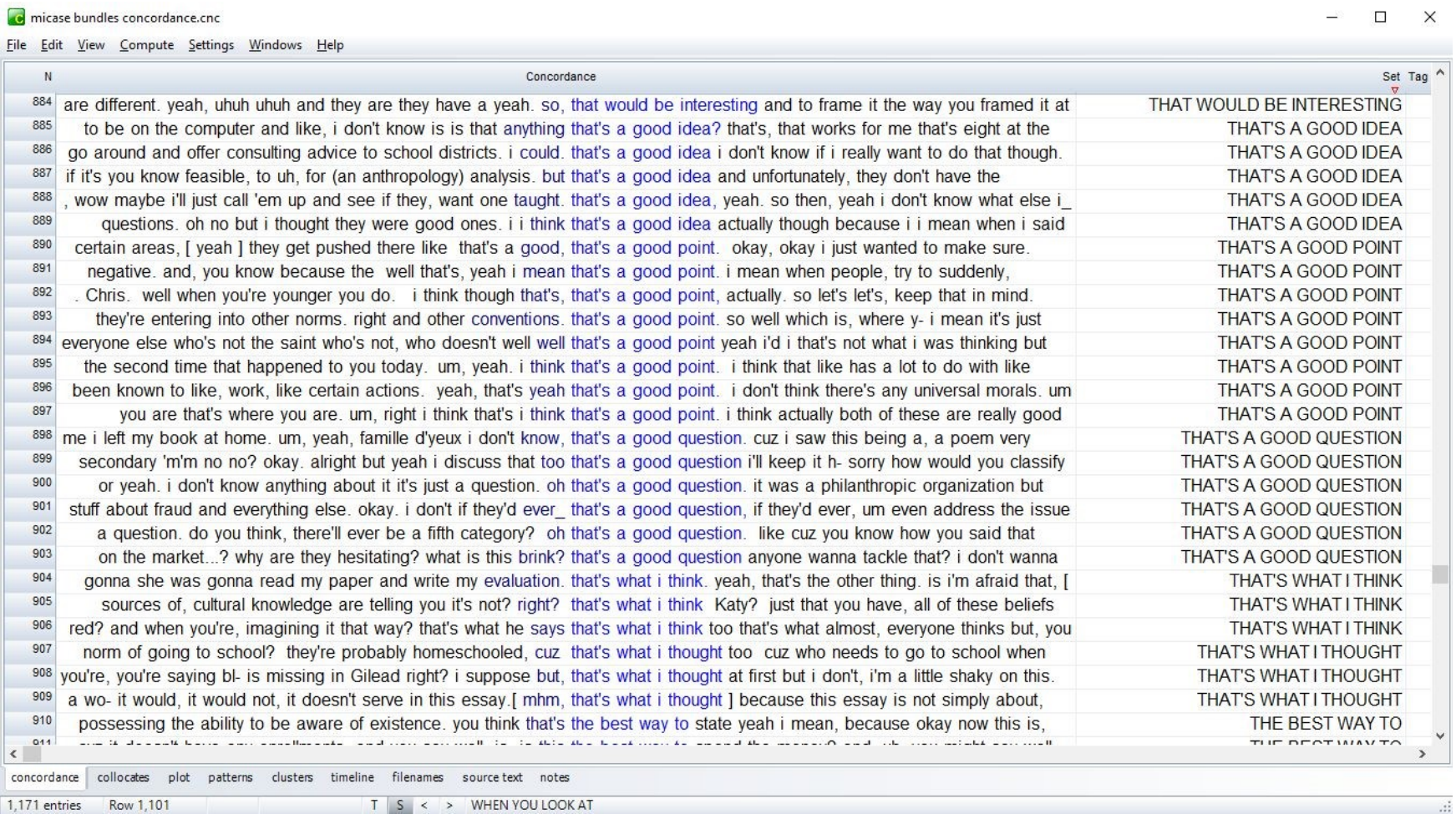

Figure 2.6 WordSmith Tools' Concordance function.

The combination of a frequency-based analysis with concordancing "allows for a detailed comparison of different genres based on quantitative evidence, and also permits more in-depth qualitative analysis of certain items chosen on the basis of those qualitative findings" (Simpson, 2004, p. 41).

The full results of the examinations of the concordance list, along with the list of lexical bundles and their functions and structural characteristics, will be reported in the next section. 


\section{Chapter 3: Results}

Before entering into a discussion of the results of this research, a restatement of the research questions which guided the study is necessary:

1. Which lexical bundles occur most frequently in spoken language in university seminars, study groups and discussion groups in the humanities and social sciences?

2. What are the functions and structural characteristics of the most frequently occurring bundles in these contexts?

In order to answer these questions, the results of this research will be organized into two sections. In the first section, an overview of the most frequently occurring lexical bundles in the MICASE Spoken Interactive Corpus (MSIC) is provided. In the following section, the functions and structural characteristics of these bundles will be assessed.

\subsection{Overview of Frequent Bundles in the MICASE Spoken Interactive Corpus Bundles} List

As described in the previous chapter, the initial search of four-word units in the corpus, with a frequency cut-off of three occurrences, yielded over 2,000 results. After applying a range criterion - that the bundles must occur in a minimum of three texts (out of a total of 14) - the total shrank to 916 entries. Finally, after a manual removal of overly specific, idiosyncratic, nonfunctional or otherwise inappropriate units, there remained a total of 183 items in the list, referred to hereafter as the MICASE Spoken Interactive Corpus (MSIC) Bundles List.

These bundles were first divided into three categories as per Biber et al.'s (2004) taxonomy, as seen in Figure 3.1 below. As the chart shows, discourse bundles were the most frequently occurring sub-type in the list, followed very closely by stance bundles. Referential bundles were somewhat less frequent. 


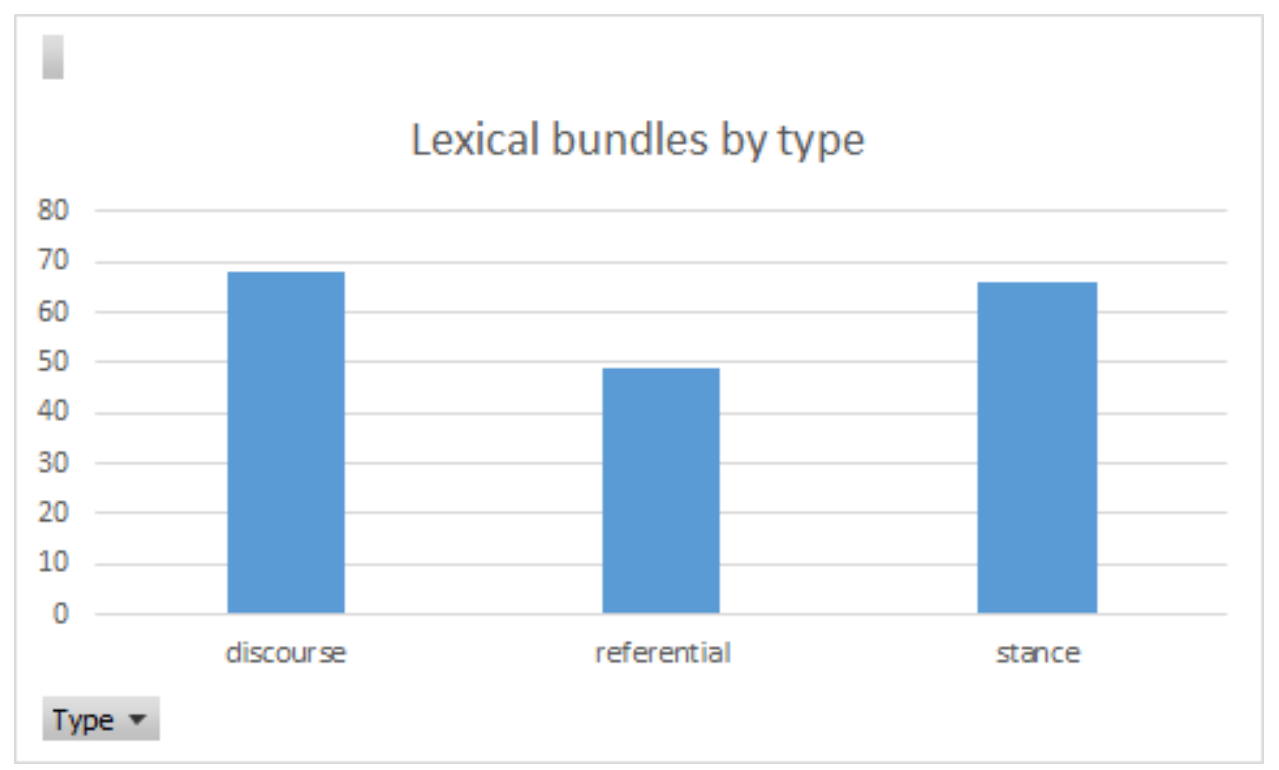

Figure 3.1 Lexical Bundles by type in MSIC Bundles List

Based on these figures, discourse bundles accounted for $37 \%$ of the total list, stance bundles comprised $36 \%$ of the total, and the remaining $27 \%$ consisted of referential bundles.

Among the discourse bundles in the list, the most frequent subtype of bundle was topic elaboration/clarification bundles. These represent $77.6 \%$ of the discourse bundles in the list, or $28.4 \%$ of the overall total. Topic introduction/focus bundles, on the other hand, account for $22.4 \%$ of discourse bundles, or just $8.1 \%$ of the list as a whole. In the more conversational and interactive environment of study groups and seminars, bundles that involve topic clarification and elaboration seem to appear more frequently than those used to introduce topics.

With regard to stance bundles, the variety of subtypes in the MSIC Bundles List is greater than with discourse bundles. Several subtypes of stance bundles are found within the list, with the most common being personal epistemic stance bundles, which made up $53.7 \%$ of stance bundles, and $19.6 \%$ of the overall list. Impersonal epistemic stance bundles were far less frequent - only three examples of these are attested in the list, accounting for just $1.6 \%$ of the overall total. 
Attitudinal and modality stance bundles were also quite frequent, accounting for $31.3 \%$ of stance bundles and $11.4 \%$ of the overall list. These were divided between the various subcategories of attitudinal and modality stance bundles. Ability stance bundles were uncommon in the list; only three examples were present, again accounting for just $1.6 \%$ of the list as a whole.

Referential bundles were the least frequently occurring type in the list, though some referential bundles were extremely frequent; five of the ten most frequently occurring bundles in the entire list fell into this category. Two sub-types of referential bundle were equally frequent in the list: bundles used for specification of attributes (intangible) and identification/focus bundles, each accounting for $27 \%$ of referential bundles, and $7 \%$ of the overall list. The remaining referential bundles consist of a mix of subtypes, with the most common being those used for specification of quantity and time reference.

Looking at the list as a whole, nearly every type of bundle listed in Biber et al.'s (2004) taxonomy is represented. An exception is the special conversational function bundle, consisting of items such as thank you very much, what are you doing and I said to her. These did not meet the frequency and range criteria to be included in the list, even prior to manual removal of unnecessary and idiosyncratic items. It would appear that contrary to what one might think, these bundles are rarely attested in the speech of study groups and seminars. It is unclear if this is a characteristic of the academic genre or of interactive speech events such as seminars and study groups, but the absence of this type of bundle cannot be ignored or simply written off as idiosyncratic.

3.2 The Functions and Structural Characteristics of Bundles in the MSIC Bundles List In order to carefully and thoroughly examine the functions of bundles in the list, this paper will focus on a selection of items rather than the entire list. By selecting the top 30 entries 
in the list, a more detailed analysis can be conducted than would otherwise be possible in the space permitted.

\begin{tabular}{|c|c|c|c|c|c|c|}
\hline Rank & Sequence & Freq. & Range & $\begin{array}{l}\% \text { of } \\
\text { texts }\end{array}$ & Type & Sub-type \\
\hline 1 & I DON'T KNOW IF & 79 & 13 & 92.86 & stance & epistemic stance (personal) \\
\hline 2 & AT THE SAME TIME & 36 & 12 & 85.71 & referential & time reference \\
\hline 3 & $\begin{array}{l}\text { OR SOMETHING } \\
\text { LIKE THAT }\end{array}$ & 33 & 9 & 64.29 & referential & imprecision \\
\hline 4 & AT THE END OF & 30 & 7 & 50.00 & referential & multi-functional reference \\
\hline 5 & THE END OF THE & 28 & 7 & 50.00 & referential & multi-functional reference \\
\hline 6 & $\begin{array}{l}\text { I DON'T KNOW } \\
\text { WHAT }\end{array}$ & 27 & 13 & 92.86 & stance & epistemic stance (personal) \\
\hline 7 & SO I DON'T KNOW & 25 & 8 & 57.14 & stance & epistemic stance (personal) \\
\hline 8 & $\begin{array}{l}\text { WHAT DO YOU } \\
\text { THINK }\end{array}$ & 24 & 8 & 57.14 & discourse & topic introduction/focus \\
\hline 9 & $\begin{array}{l}\text { A LITTLE BIT } \\
\text { ABOUT }\end{array}$ & 22 & 8 & 57.14 & discourse & topic introduction/focus \\
\hline 10 & A LOT OF THE & 22 & 5 & 35.71 & referential & quantity specification \\
\hline 11 & I THINK IT WAS & 21 & 10 & 71.43 & stance & epistemic stance (personal) \\
\hline 12 & KNOW WHAT I MEAN & 20 & 9 & 64.29 & discourse & topic elaboration/clarification \\
\hline 13 & IF YOU LOOK AT & 17 & 8 & 57.14 & discourse & topic introduction/focus \\
\hline 14 & $\begin{array}{l}\text { WHAT DO YOU } \\
\text { MEAN }\end{array}$ & 17 & 7 & 50.00 & discourse & topic elaboration/clarification \\
\hline 15 & I DON'T KNOW HOW & 16 & 9 & 64.29 & stance & epistemic stance (personal) \\
\hline
\end{tabular}




\begin{tabular}{|c|c|c|c|c|c|c|}
\hline 16 & IT SEEMS TO ME & 16 & 7 & 50.00 & stance & epistemic stance (personal) \\
\hline 17 & $\begin{array}{l}\text { YOU DON'T HAVE } \\
\text { TO }\end{array}$ & 14 & 8 & 57.14 & stance & $\begin{array}{l}\text { attitudinal/modality stance } \\
\text { (obligation/directive - personal) }\end{array}$ \\
\hline 18 & I THOUGHT IT WAS & 13 & 9 & 64.29 & stance & epistemic stance (personal) \\
\hline 19 & TO BE ABLE TO & 13 & 9 & 64.29 & stance & ability (impersonal) \\
\hline 20 & $\begin{array}{l}\text { ON THE OTHER } \\
\text { HAND }\end{array}$ & 12 & 7 & 50.00 & discourse & topic elaboration/clarification \\
\hline 21 & IN THE CASE OF & 12 & 6 & 42.86 & referential & specification of attributes (intangible) \\
\hline 22 & ON THE ONE HAND & 12 & 5 & 35.71 & discourse & topic elaboration/clarification \\
\hline 23 & $\begin{array}{l}\text { A CERTAIN } \\
\text { AMOUNT OF }\end{array}$ & 10 & 6 & 42.86 & referential & quantity specification \\
\hline 24 & IN THE SAME WAY & 10 & 5 & 35.71 & referential & specification of attributes (intangible) \\
\hline 25 & IT SEEMS TO BE & 10 & 4 & 28.57 & stance & epistemic stance (impersonal) \\
\hline 26 & IN THE SENSE THAT & 10 & 3 & 21.43 & referential & specification of attributes (intangible) \\
\hline 27 & ONE OF THE THINGS & 9 & 6 & 42.86 & referential & identification/focus \\
\hline 28 & $\begin{array}{l}\text { WHEN YOU TALK } \\
\text { ABOUT }\end{array}$ & 9 & 6 & 42.86 & referential & time reference \\
\hline 29 & A LITTLE BIT OF & 9 & 4 & 28.57 & referential & quantity specification \\
\hline 30 & $\begin{array}{l}\text { THAT'S A GOOD } \\
\text { POINT }\end{array}$ & 9 & 4 & 28.57 & stance & epistemic stance (personal) \\
\hline
\end{tabular}

Figure 3.2 Top 30 frequent bundles in MSIC Bundles List

As is clear from the list, a variety of bundle types and subtypes are present. Eleven stance bundles, eleven referential bundles and eight discourse bundles comprise the top 30 entries proportions rather different from the overall total, in which discourse bundles are the most 
frequent type, followed by stance bundles and finally referential bundles. These results are contrary to those of Biber and Barbieri (2007) who examined the presence of lexical bundles across several types of speech encounters in a university setting. They found that stance bundles were dominant in spoken university registers, accounting for more than $60 \%$ of bundles in study groups; discourse organizers were a very distant second (Biber \& Barbieri, 2007). However, the distribution of subtypes of stance bundles in their corpus of study groups is similar to that of the MSIC. Epistemic stance bundles were the most frequent type of stance bundle in study groups, followed closely by obligation bundles - proportions similar to those found in the present study. Biber and Barbieri assert that the reason for this is that stance bundles in study groups "usually function to hedge claims rather than asserting certainty" (2007, p. 276). Several examples of this can be found within the top 30 items in the MSIC Bundles List, such as I don't know if, I don't know how and $I$ thought it was.

We now turn to a discussion of each of the top 30 items in the MSIC Bundles List. We will look at each item and briefly discuss its function, its structural characteristics (based on Biber et al., 2004), frequent collocates and semantic transparency or opacity.

1. Lexical bundles that incorporate verb phrase fragments

1a. $($ connector + ) $1 \mathrm{st} / 2$ nd person pronoun $+\mathrm{VP}$ fragment

1b. $($ connector + ) 3rd person pronoun + VP fragment

1c. Discourse marker + VP fragment

1d. Verb phrase (with non-passive verb)

1e. Verb phrase with passive verb

1f. Yes-no question fragments

1g. WH-question fragments

2. Lexical bundles that incorporate dependent clause fragments

2a. 1st/2nd person pronoun + dependent clause fragment

b. WH-clause fragments

2c. If-clause fragments

$2 \mathrm{~d}$. (verb/adjective + ) to-clause fragment 
2e. That-clause fragments

3. Lexical bundles that incorporate noun phrase and prepositional phrase fragments

3a. (connector + ) noun phrase with of-phrase fragment

3 b. Noun phrase with other post-modifier fragment

3c. Other noun phrase expressions

3d. Prepositional phrase expressions

3e. Comparative expressions

Figure 3.3 Structural types of lexical bundles (Biber et al., 2004, p. 381)

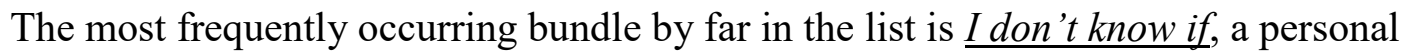
epistemic stance bundle generally used to express uncertainty about a situation or state, or, as previously discussed, to hedge a claim that is being made. This bundle occurs in nearly every text in the corpus and is more than twice as frequent as the second bundle in the list. This bundle is a verb phrase with a first-person pronoun and a dependent clause fragment. An examination of the concordances of this bundle shows that it is almost always used at the beginning of a sentence or clause. If it is preceded in a clause or sentence, the preceding item generally takes the form of a filled pause or stutter; the most frequently occurring items immediately to the left of $I$ don't know if are I, um, like, so, and yeah. Immediately following this bundle is in most cases a personal pronoun, most frequently I, you, she, he, anyone, anybody, and we. Other frequent items following this bundle include that, it's, there's, this and it. This bundle is perhaps one of the most frequently-occurring and effective ways of expressing doubt or uncertainty in the English language.

It should be noted that in conversation this bundle is often used in place of I don't know whether, despite the fact that the meaning of the two bundles is not precisely the same. I don't know whether (which occurs only seven times in the entire corpus, across three texts) tends to be used in more formal situations, which would explain its relatively infrequent status in the MSIC. 
The second most frequent bundle is at the same time, a referential bundle that is - at least in theory - used as a time reference. A look at the concordances of this bundle shows that it is indeed often used in this manner - indicating events occurring concurrently. In this case it often marks the end of a sentence, while no single preceding word is especially frequent. However, this bundle is also often used to express a different meaning, roughly equivalent to the word nevertheless or the phrase all the same. In this case it is most often preceded by but, or can be the first element in a sentence; there are no particular patterns to the word that follows the bundle. This particular sequence is notable due to the two different functions it can perform. Its dual nature means that care would need to be taken in teaching this bundle to non-native speakers; its two meanings would need to be careful explained. This might prove troublesome due to the fact that one of its functions - time reference - is semantically transparent, whereas its other meaning is not. This bundle is a prepositional phrase expression, incorporating a noun phrase and a prepositional phrase fragment.

The third bundle on the list is or something like that, a referential bundle used to express imprecision. Structurally, it falls into the miscellaneous category of "other noun phrase expressions". The most common use of this bundle is after giving an example of something, in order to show that said example may not be perfectly accurate. It is usually preceded by a noun; as this sequence can be used after nearly any noun in the language, there are no particularly frequent preceding nouns in the corpus. In most cases this bundle is the final element in a sentence or clause. This bundle is more or less semantically transparent; if it is understood that the word that refers to the element previously mentioned, it is relatively easy to discern the meaning of this bundle. It is possible that a non-native speaker might not understand why this 
bundle uses that rather than this, these or those; an explanation might be needed. Structurally, it falls into miscellaneous category of "other noun phrase expressions".

The next two bundles in the list, at the end of and the end of the, are best discussed as a pair. These are referential bundles that are classified as "multi-functional references" - they can be used to describe, for example, a time period (the end of the day) or a physical location (the end of the hallway). What is unique about these bundles is that these they often combine to make the single five-word sequence at the end of the. However, this was not always the case in the MSIC. The sequence at the end of was sometimes followed by that, it, all, or $a$. Likewise, the bundle the end of the was in some cases preceded by to or other less-frequent words. Frequently, however, these two sequences can be seen as two halves of the larger bundle. Whether or not they should be taught separately or as a single unit is best left to the instructor's discretion. These bundles are semantically transparent, though they may be used in a phrase or sentence that is not semantically transparent. For example, the expression at the end of the day can literally mean at the end of a 24-hour period of time (or at the end of work hours or waking hours), but can also be used to mean ultimately. In this case, while the bundle itself might have semantic transparency it would still need to be clarified for a learner of English as a second language. The end of the is a noun phrase with an of-phrase fragment, while at the end of is a prepositional phrase.

Moving down the list we next encounter the personal epistemic stance bundle $\underline{I \text { don't }}$ know what, which occurs in thirteen of the fourteen texts included in the corpus. This bundle consists of a first-person pronoun and a dependent clause fragment. Much like its cousin I don't know if which we found at the top of our list, it is used to express uncertainty or hedge a claim. This bundle frequently occurs at the beginning of a sentence or clause. When it does not, it can be preceded by any number of different words and word classes, with no apparent patterns. 
Similarly, there are few patterns to what follows this bundle. This bundle is semantically transparent, and as a result it and similar bundles such as I don't know where, I don't know when, I don't know how, I don't know who and I don't know why could potentially be taught as a group. While none of these save $I$ don't know how are in the 30 most frequent items in the corpus, indicating that they are not exceedingly common, the similar way in which these bundles are formed might make it worthwhile to teach them together.

The next item on the list is the sequence so I don't know, which consists of a connector plus a first-person pronoun and a verb phrase fragment. This is another personal epistemic stance bundle which can stand alone or which can combine with either of the previously-discussed bundles I don't know if and I don't know what, along with several other less-frequent sequences such as I don't know where or I don't know who. However, in the MSIC, relatively few of these combinations occurred. The five-word bundle so I don't know if occurred three times, as did so I don't know how. Surprisingly, in most of its occurrences this bundle stood alone as a single unit. It appears from the distribution of these bundles in the corpus that it is the particular combination of so I don't know which is frequent in academic conversation, indicating that it is this bundle alone among the various permutations that is necessary to teach. However, as with the previous entry on the list, an argument could be made that the various combinations should be taught together for the sake of clarity.

The discourse bundle what do you think, which structurally is a WH-question fragment, is used for topic introduction and focus, something that occurs very frequently in academic speech in interactive contexts. It is easy to see the importance of this bundle for participants in seminars and discussion groups; these contexts often involve the sharing of opinions and ideas. In the MSIC, this bundle sometimes is a sentence unto itself, without any additional words, though 
more often than not an additional clause follows. It is sometimes preceded by the word so, forming the five-word bundle so what do you think. When the bundle does not end the sentence, it is most often followed by about or of, in which case the subject for which the speaker is requesting the listener's opinion is specified.

As with other question-word based bundles discussed above, similar WH-question fragment bundles exist such as where you do think, why do you think, how do you think, when do you think and who do you think. However, these bundles are surprisingly uncommon in the MSIC. After what do you think, the next most frequent of these bundles is why do you think, which occurs just four times in three different texts. How do you think occurs only once, and none of the other forms of this bundle occurred at all in the corpus, indicating that they may not be used as frequently as one might think, at least in the context of interactive academic discourse. A little bit about is another topic introduction and focus discourse bundle that appears frequently in the MSIC. It consists of a noun phrase (a little bit) combined with a post-modifier fragment (about). This conversational bundle usually occurs with the verb talk, and is most often followed by a determiner such as the or that. As a result, this sequence could potentially be a part of a five- or even six-word sequence, such as talk a little bit about or talk a little bit about the. This is a good example of a bundle that would be far more frequently attested in conversation than in academic writing - such informal language would be considered inappropriate for an academic paper.

It could be argued that this bundle lacks semantic transparency, or at least specificity. The noun phrase a little bit refers to an unknown quantity of something - whether tangible or intangible. In the case of this bundle, it perhaps most often refers to time or knowledge. However, non-native speakers of English may be uncertain as to how this bundle is used or what 
quantities qualify as "a little". It would be necessary to spend some time explaining this in order to help learners use this bundle effectively in conversation.

A lot of the is a versatile referential bundle, used for specification of quantity. Structurally it falls into the category of "other noun phrase expressions". While it does not denote an exact quantity, it can be used for both count and noncount nouns. It is usually followed by a noun phrase, though there are no specific words that frequently follow it in the MSIC. It can be found at the beginning of a sentence or clause, or in the middle, but it is grammatically impossible for it to exist at the end of one. It should be noted that this bundle was found in relatively fewer texts than many of the bundles on the list, appearing only in five of fourteen transcripts. However, this was above the frequency cut-off point, and anyone who has regularly participated in academic conversation can attest that this bundle does occur quite frequently and merits inclusion in this list.

As with the bundle a little bit about, it would not necessarily be clear to a non-native speaker of English what the phrase a lot means. It would be important to impress upon the learner that the meaning of such phrases is nonspecific and subjective, but that there often are generally accepted ideas for what constitutes "a lot" or "a little". This knowledge could better equip learners to use these bundles effectively.

I think it was is a personal epistemic stance bundle used to express an opinion, generally about something in the past. Its structure consists of a first-person pronoun and a verb phrase fragment. It can be found at the beginning of a sentence or clause, or at the end (though no examples of the latter exist in the MSIC). Most of the collocates preceding this sequence in the MSIC indicate that the speaker was stuttering, as they include such words as $u$, like, think and 
was. In several cases the word that follows this bundle is a proper noun, indicating that it is often used to identify a previous speaker, as in the following example found in the MSIC:

now, $i$ think it was Missy who said that...

A comparable bundle is the present-tense version I think it is, which also consists of a first-person pronoun and a verb phrase fragment. However, this bundle is found far less frequently, appearing only ten times in the entirety of the MSIC, across seven different texts. A likely reason for this is that in conversation speakers tend to contract the last two words of this bundle into it's, forming the three-word sequence I think it's. Predictably, as a three-word bundle I think it's is extremely common in the MSIC, appearing 68 times in thirteen texts. However, as this is a three-word bundle it is not included in this list. It would, however, certainly be worth informing learners that when using the present tense form of I think it is in conversation, it is probably a better idea to use the contracted three-word version.

Know what I mean is an example of a bundle that would only be found in conversation, and never in academic writing. This discourse bundle is a verb phrase which carries a nonpassive verb, and is used for topic elaboration and clarification - most frequently occurring at the end of a statement as an interrogative to elicit a response from listeners. It should be noted that in MSIC, when this bundle marks the end of a turn, it is usually followed by a simple affirmative response such as $u h$ huh, right or yeah, indicating that the response to this bundle is not especially important. The bundle often seems to be used to check whether or not the listener understands or is following what the speaker is saying. When the speaker's turn continues after this bundle, it is often followed by non-linguistic words such as like if the sentence continues.

Essentially, this bundle is an abbreviated version of the phrase do you know what I mean, with the first two words omitted. This six-word phrase, however, is found only four times in the 
entire corpus, while the five-word sequence you know what I mean - without the preceding do occurs sixteen times. As the four-word bundle occurs twenty times in the corpus, it appears that know what I mean is perhaps the most frequently used form of this expression, and therefore has the most value for instruction. However, in most cases in the MSIC, this sequence is actually part of the five-word bundle you know what I mean, and can also be part of the six-word bundle do you know what I mean. Nonetheless, it merits inclusion because it can and does occur as a fourword bundle with the you dropped. This most likely would occur in informal conversation, but the bundle could legitimately be used this way in the contexts discussed in this study.

If you look at is a discourse bundle used for topic introduction and focus. One of the few if-clause fragments found in this list, it is most often preceded by and, although it is also frequently used at the beginning of a sentence or clause. It is impossible for this bundle to occur at the end of a sentence or clause, and it is most often followed by determiners such as it, the and some, usually as part of a noun phrase. It is generally used to call attention to a particular topic or example. This bundle is not entirely semantically transparent; the phrasal verb look at can be used for a literal meaning of focusing one's eyes in a particular direction, or it can mean examine or investigate. As a result, it would be necessary to inform learners of the more common meaning of this bundle.

Depending on how it is used, this bundle may or may not be semantically transparent. In some cases the constituent parts may be used in a literal sense, such as in the phrase if you look at page fifty-five. However, there are only two examples of this in the MSIC, whereas the other occurrences of this bundle use if you look at to mean if you consider or if you examine. This use of this bundle appears to be much more common, and therefore it appears likely that it in the majority of cases this bundle is not semantically transparent. A non-native speaker of English 
might not understand how one can "look at" something intangible, such as in the MSIC example if you look at culture as a system of values.

The discourse bundle what do you mean is one that occurs frequently in conversation. A WH-question fragment generally used for topic elaboration and clarification, it is capable of forming a complete sentence on its own, or can occur as part of the five-word bundle what do you mean by (in which case it must be followed by another clause, typically led by a determiner such as that). In the MSIC the latter case does occur, but equally frequently this bundle comes at the end of an utterance. It is also occasionally followed by another bundle, when you say that, which is itself not frequent enough in the corpus to merit inclusion in this list. As what do you mean usually occurs at the beginning of a sentence, there are no particularly frequent collocates preceding it in the MSIC.

I don't know how is a personal epistemic stance bundle. It consists of a first-person pronoun and a dependent clause fragment. It is used to hedge, or as an expression of one's lack of knowledge, and occurs in a variety of contexts. It is preceded by so with enough frequency that it could be argued that it sometimes forms a five-word bundle, so I don't know how. Contrary to expectations, it is not often followed by to in the MSIC, indicating both that it rarely is part of the five-word bundle I don't know how to, and that this sequence is not always used to express a lack of knowledge regarding the carrying out of an action (though this is a frequent function of this bundle). A wide variety of words can follow, with few apparent patterns. Essentially, this bundle can be employed in many situations in which it is necessary to express a lack of knowledge. It would be worthwhile from a pedagogical perspective to teach this bundle together with I don't know if and I don't know whether, in order to equip learners with adequate tools to express a lack of knowledge in any semantic context. 
It seems to me is a personal epistemic stance bundle which is used most frequently to preface one's own opinions or observations. It consists of a third person pronoun and a verb phrase fragment, and it often is found at the beginning of a sentence or after a comma or other punctuation marker. In nearly every example in the MSIC it is followed by that, indicating that in many cases this bundle is actually a component of the five-word bundle it seems to me that; in these cases, this bundle typically is followed by a relative clause. However, it is important to note that in both speech and writing, relative clauses are often reduced. Speakers often omit the word that while retaining the same meaning as if the word had been used; the difference in meaning between the phrases it seems to me that he's right and it seems to me he's right is negligible. With that in mind, it might be worthwhile to accept this as a four-word bundle, or at least to introduce it to learners as both a four- and five-word bundle, depending on their familiarity with reduced relative clauses.

The bundle you don't have to is a stance bundle which falls into the subcategory of attitudinal/modality stance, relating specifically to personal obligation or directive. It consists of a second person pronoun and a verb phrase fragment, and it is frequently found at the beginning of a sentence, though sometimes it is preceded by metalinguistic items such as $u h$ and/or discourse markers such as I mean in the MSIC. In every case it is followed by a verb, save only a lone example where this bundle is found at the end of a sentence. In this case the bundle itself actually composes an entire sentence, something that does occur in spoken English. This bundle includes a contraction, making it a cognate of the five-word bundle you do not have to. However, it is important to note that the contracted version of this bundle is much more likely to appear in conversation, to the point where its uncontracted counterpart would sound unnatural. As a result, 
if these bundles were to be taught to students of English as a second language, it would be more worthwhile to teach the contracted form.

The personal epistemic stance bundle I thought it was is composed of a first-person pronoun and a verb phrase fragment. It can be used for two main purposes: first, it can be used to express an opinion regarding an event in the past, or regarding something that the speaker experienced in the past. In the MSIC, examples of this use include I thought it was interesting and I thought it was good. This is the most common use of this bundle in the MSIC. The other primary use of I thought it was is when the speaker is attempting to reconcile a previously held belief or a piece of information previously held to be true with new information indicating that these may be false. For example, one case of this use in the MSIC is I thought it was in Tulsa. In this case the speaker is expressing a previously held belief that something was located in the city of Tulsa, when presented with evidence to the contrary. This use also can act as an acknowledgement that a previous belief was false. The bundle can appear at the beginning of a sentence or in the middle of one, but cannot end a sentence or clause.

As a result of these two similar yet distinct meanings, it would be important for an instructor to address this bundle carefully. One meaning seems to be more transparent than the other; the function of expressing an opinion about a past event would be easier for learners to grasp than its other function.

To be able to, a personal ability stance bundle, is a to-clause fragment. This bundle is quite useful. It can be used to discuss both one's own ability and the ability of others to do something. In all cases this bundle is followed by a present tense verb, and in the MSIC a wide variety of verbs follow. There are no particularly frequent verbs, a range of verbs such as get, tell, speak, do and make are represented. While it is possible for a sentence or clause to begin 
with this bundle (as in the example to be able to speak two languages is very useful), no examples of this exist in the MSIC. This sequence is semantically transparent and should be readily understandable if a learner is aware of the meaning of the adjective able.

On the other hand is a discourse bundle that falls under the category of topic elaboration or clarification. It is a prepositional phrase expression, and is one of the more idiomatic bundles found in this list, as its meaning is not readily apparent from its component parts. It is generally used for comparison and contrast of two distinct ideas or situations. It is sometimes preceded by but (either with or without an intervening comma), and an argument could be made that in some cases this bundle is part of the five-word bundle but on the other hand, in most cases in the MSIC, however, this is not the case. This bundle can be found at the beginning or end of a sentence or clause, but often falls in the middle. This bundle is related to the four-word bundle on the one hand, which will be discussed below.

The discourse bundle in the case of is a prepositional phrase expression which falls under the category of topic elaboration and clarification. In use, its function is roughly equivalent to the phrase as for; it specifies the topic or example that is about to be discussed. This bundle can be found at the beginning or in the middle of a clause, but cannot exist at the end; it is always followed by a noun phrase. It is not entirely semantically transparent, as it can be assumed that non-native speakers might confuse this sequence with the three-word bundle in case of, which, while similar structurally, bears an entirely different meaning. This is a potential area of difficulty for second language learners; the similarity of these phrases, combined with the tendency of native speakers to reduce sounds such as the, could very well lead to confusion.

On the one hand is a discourse bundle used for topic elaboration and clarification. A prepositional phrase expression, it is associated with the bundle on the other hand (as well as the 
five-word bundle but on the other hand) which appears earlier in this discussion. The two bundles are often used together in order to examine two different questions or two sides of a single problem. On the one hand must precede on the other hand. It was expected that on the other hand would usually be paired with on the one hand, but a careful examination of the concordances of on the one hand reveals that this bundle often appears without its counterpart, at least in MSIC. This may be the result of the natural ebb and flow of interactive speech - a speaker intends to follow his initial utterance with a second, beginning with on the other hand, but is interrupted or digresses into another topic. Structurally it is similar to on the other hand, in that it can be preceded by the word but, can be found at the beginning or end of a sentence or clause, as well as in the middle. As with its counterpart, this bundle lacks semantic transparency. It should be noted that this bundle may also occur in a three-word form: on one hand. This form bears the same meaning as its longer counterpart.

The referential bundle a certain amount of is composed of a connector, a noun phrase and an of-phrase fragment. While this bundle is ostensibly used for quantity specification, it is important to note that despite this purpose this bundle cannot specify a precise quantity. As a result, it can be argued that this bundle is not semantically transparent. To a non-native speaker, the meaning of this bundle would be assumed to be "a known quantity of something". However, in use, this bundle's meaning is closer to "an unknown amount of something", roughly equivalent to the word "some". It is in all cases followed by a noun, and while it can occur at the beginning of a clause or sentence, in most cases in the MSIC it does not. The noun following this bundle is in most cases an uncountable noun. In cases where a countable noun would be used it would be more accurate to use the similar bundle a certain number of; however, in practice it is common for a certain amount of to be used with countable nouns. 
In the same way is a referential bundle, used for the specification of intangible attributes. It is a prepositional phrase expression and, as its component parts suggest, it is used to draw a comparison between the attributes of two actions or ideas. It functions similarly to the word similarly, indicating the items being compared are the same or nearly so, or share some common characteristic. This bundle can occur at the beginning or end of a sentence or clause, though there are few examples of this in the MSIC; it most often occurs mid-clause or mid-sentence.

The next item is the impersonal epistemic stance bundle it seems to be. This bundle consists of a third-person pronoun and a verb phrase fragment, and is used when the speaker wants to express his or her interpretation or analysis of something while hedging or maintaining a degree of uncertainty. It is sometimes preceded by and, but it is unlikely that this would constitute a five-word bundle as and does not contribute in any significant way to the meaning of the subsequent four-word sequence. This bundle is capable of appearing at the beginning or end of a clause or sentence, though in most cases in the MSIC it appeared in the middle of a clause without a punctuation boundary on either side.

The presence of the neutral third-person pronoun it indicates that this bundle is used only for inanimate objects or abstract concepts (more frequently the latter) rather than for people. Equivalent bundles such as you seem to be, he seems to be, she seems to be, and they seem to be are attested in MSIC, though less frequently than the it variation. Negated forms tend to comprise five- or six-word bundles, such as it doesn't seem to be or it does not seem to be. In order to teach these bundles in an academic English context it would be necessary to include both the original and negated forms, along with the second- and third-person pronoun variants. A possible area of confusion could be the aforementioned bundle it seems to me; the differences between these two sequences would need to be clarified for language learners. 
In the sense that is a referential bundle consisting of a prepositional phrase expression and is used for the specification of intangible attributes. It appears to most frequently be used in order to limit the meaning of something that is being specified, or to distinguish between multiple possible meanings, as in the example:

the Apabhramsa is is [sic] a vernacular in the sense that it is not Sanskrit, but is a literary language...

In this example from the MSIC, the bundle is being used to place a limit on, or to clarify, the word vernacular. Based on examples from the corpus, this bundle is usually preceded by an adjective or noun, and almost always occurs mid-sentence. In general, it is not used at the beginning or end of a sentence or clause. While a few examples of this occur in the MSIC, these are most likely due to speaker error. Frequent preceding collocates include argument and valid, while the most frequently occurring collocate following the bundle is $i t$.

This bundle's semantic transparency is debatable. The word sense has multiple meanings which may not always be readily apparent to a learner of the language. It could be argued that this bundle is not transparent, as its component parts do not make its meaning especially clear.

It is perhaps worth noting that this bundle appeared in only three of fourteen texts, meaning it attained the absolute minimum frequency to be included in the list. Looking at its use in context, it appears that this bundle has a tendency to appear repeatedly within a short period of time, or not at all; this indicates that its use is either somewhat idiosyncratic or that it is used only in specific contexts. The decision to keep it in the list was based on the fact that its use in context did appear to be appropriate; it was difficult to think of a clearer way to express the ideas of the various speakers who used this bundle. 
One of the things is a referential bundle used for identification or focus and consisting of a noun phrase with an of-phrase fragment. Specifically, it is used to focus on one of a set of items, whether tangible objects or abstract contexts. This bundle can occur at the beginning of a sentence or clause, but does not appear at the end. The most frequent preceding collocate in MSIC is and, while the most frequently occurring collocate following the bundle is that. In some cases it is possible that this could constitute a five-word bundle, one of the things that; however it is certainly not always the case. This bundle can often be followed by a personal pronoun such as he, she or I, particularly when referring to past speech, such as one of the things he said.

This bundle is entirely semantically transparent; it should not be especially challenging for a learner of the language to understand based solely on its constituent words. It could potentially be taught alongside similar bundles such as one of these things or one of those things. However, these bundles are much less frequent (one of these things occurs only once, and one of those things does not occur at all in the entire corpus) and therefore their usefulness is highly questionable. This is another example of where a native speaker's intuition and/or expectations are contradicted by real-life data. It would be easy to assume that these two bundles occur with similar frequency as one of the things, but this is clearly not the case.

When you talk about is a referential bundle, composed of a connector, a second person pronoun and a verb phrase fragment. The specific type of reference for which this bundle is used is time reference - at least, this is what is appears to be at first glance. Its function is not always entirely clear, however. This bundle does, in some cases, appear to refer to a specific time - the time at which an individual (identified by the second-person pronoun you) discusses something, as in the following example:

When you talk about your children, your eyes light up. 
However, it often appears to hold a meaning similar to the phrase on the subject of or the word regarding. When used in this manner the generic you is used to refer to individuals in general. to Examples of this can be seen in MSIC, such as I think that's important to look at when you when you [sic] talk about issues of equity. It appears to be this latter use that is more frequent, at least in MSIC. As a result, it can be said that this bundle lacks semantic transparency in some cases. This, combined with its dual meaning, indicates that this bundle would need some special attention in order to be presented to second language learners.

It should be noted that there are a number of variants of this bundle that use either firstperson or third-person pronouns, such as when I talk about, when he talks about, when she talks about and perhaps most significantly when we talk about. While the first three bundles bear the literal meaning described above, when we talk about functions in a manner nearly identical to when you talk about. Examples of this bundle did occur in MSIC, as in the following example: Today when we talk about fantastic literature we usually think it's fiction right? However, while this bundle met the frequency criteria for inclusion in the list (it occurred four times in the corpus) it did not appear in a sufficient range of texts (only two texts contained this bundle) and was therefore not included. Nevertheless, it would certainly be worth teaching this bundle alongside when you talk about, as its function appears nearly identical.

Finally, the sequence when one talks about carries the same function as when you talk about and when we talk about. However, this bundle did not occur at all in MSIC, and therefore it appears that this form is too archaic to appear in academic conversation. As a result, it would be difficult to justify its inclusion in EAP instruction.

A little bit of, a referential bundle used for quantity specification, is very similar to the bundle a certain amount of which occurred earlier in this list. Like its cousin, it consists of a 
connector, a noun phrase and an of-phrase fragment. Also like a certain amount of, it does not actually specify a precise quantity and therefore is not entirely semantically transparent - the quantity a little being entirely subjective. It also shares the limitation of being used for only noncount nouns; however, unlike a certain amount of, this limitation is actually observed. Few native speakers would follow the bundle a little bit of with a countable noun. No examples of this are found in the MSIC; the words that follow this sequence are typically non-count nouns such as history, or demonstrative determiners such as this or that. Of course, this bundle cannot be found at the end of a sentence or clause; it must be followed by a noun phrase.

This sequence is one that would be unlikely to appear in written academic discourse. The phrase a little bit is highly conversational; it would be considered unsuitable for academic writing and would most likely be replaced by some or a small amount/quantity of.

The last of the top 30 items in the list is the personal epistemic stance bundle that's a good point. It appears to fall into the miscellaneous category of other noun phrase expressions. This bundle can be an entire clause or sentence unto itself; it does not need to be preceded or followed by a word or phrase. However, there are not many examples of this in the MSIC; while this sequence usually occurs at the end of a sentence it is often preceded by I think, I mean or yeah. None of these collocates are frequent enough to be considered part of a larger bundle with that's a good point, however. This bundle is a contracted form of the sequence that is a good point; however, this sequence is rarely attested in conversation as native speakers of English have a tendency to contract that is in nearly all cases. Perhaps unsurprisingly, the full five-word sequence does not occur at all in the MSIC.

This bundle is more or less semantically transparent; provided that a learner of English is aware of the abstract meaning of point, the meaning of this sequence is clear from its component 
parts. As with many other bundles on this list, it is unlikely that this bundle would appear in academic writing. The contraction of that is to that's, combined with the relative lack of precision of the adjective good, make it unsuitable for use in written academic discourse. In conversation, however, this bundle is highly useful; it functions not only as a way of expressing one's own stance about a point expressed by a speaker but also can be used almost as a discourse bundle. That is, it can be used to show a speaker that one understands and agrees with what is being said.

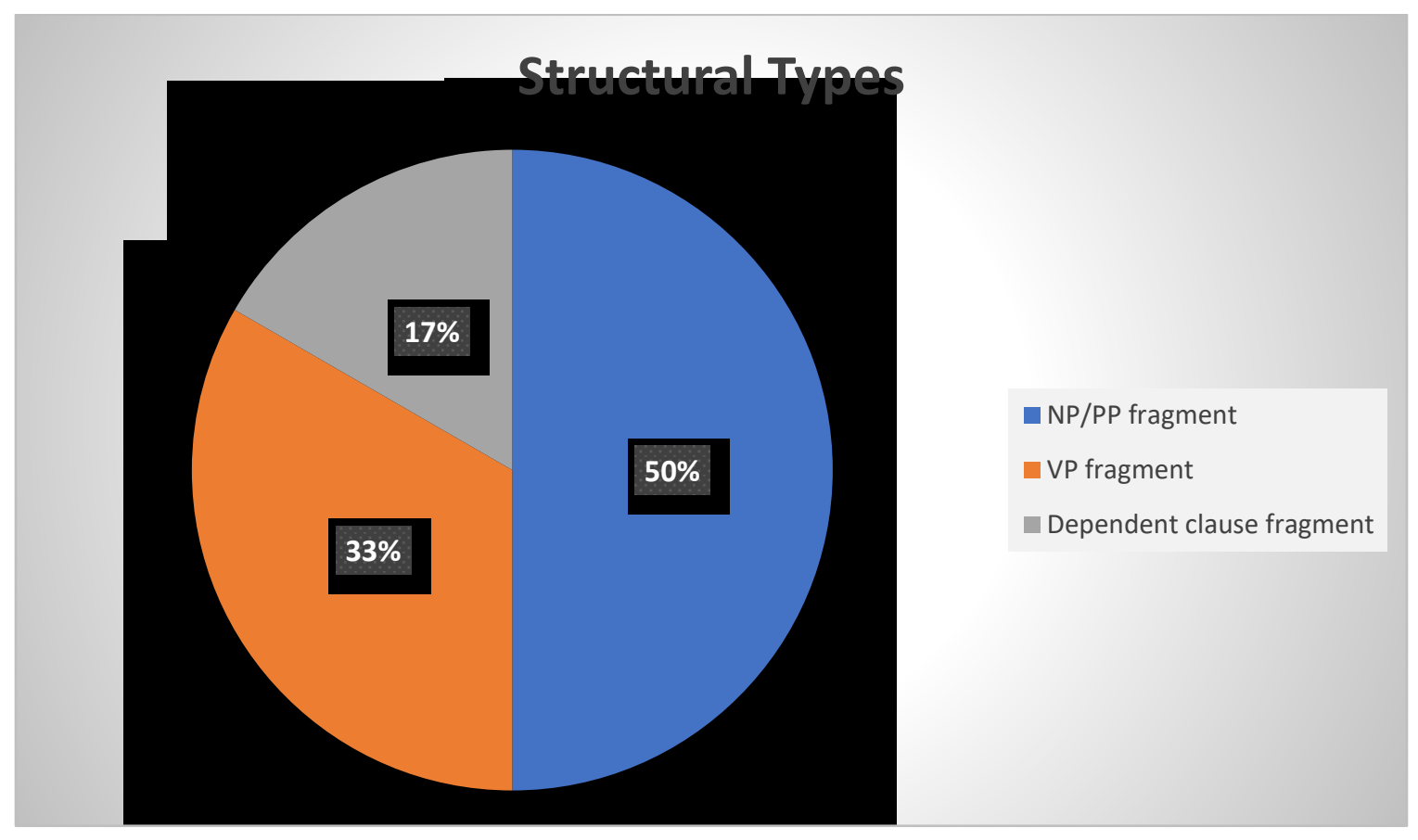

Figure 3.4 Structural types of lexical bundles in the top 30 entries.

Having examined these 30 items in some detail, some patterns are clear. The proportions of the various lexical bundle types in this sub-list have already been addressed, and so we now turn to a discussion of the structural types of bundles which are present. Unsurprisingly, a variety of categories appear in the list. The third major category of Biber et al.'s (2004) structural types lexical bundles that incorporate noun phrase and prepositional phrase fragments - is the most frequent in this group, accounting for half (15) of the items in the list. From this category, the 
most frequent subtype of bundle present in this list is prepositional phrase expressions (seven items) followed by (connector+) noun phrase with of-phrase fragment (four items). Three items fell into the "other noun phrase expressions" category, while a single item was categorized as a noun phrase with other post-modifier fragment.

Second most frequent among the major categories were lexical bundles incorporating verb phrase fragments, with a total of ten items from the list being included in this category. Of these, the most frequent subtype was (connector+) first/second person pronoun + verb phrase fragment (five items) followed by (connector+) third person pronoun +verb phrase fragment (two items), WH-question fragments (two items) and verb phrases with non-passive verb (one item).

The least frequent category was lexical bundles incorporating dependent clause fragments, with only five of the top 30 bundles in the list being categorized as such. Of these the most frequent subtype was first/second person pronoun + dependent clause fragment (three items) followed by if-clause fragments and (verb/adjective+) to-clause fragment (one item each).

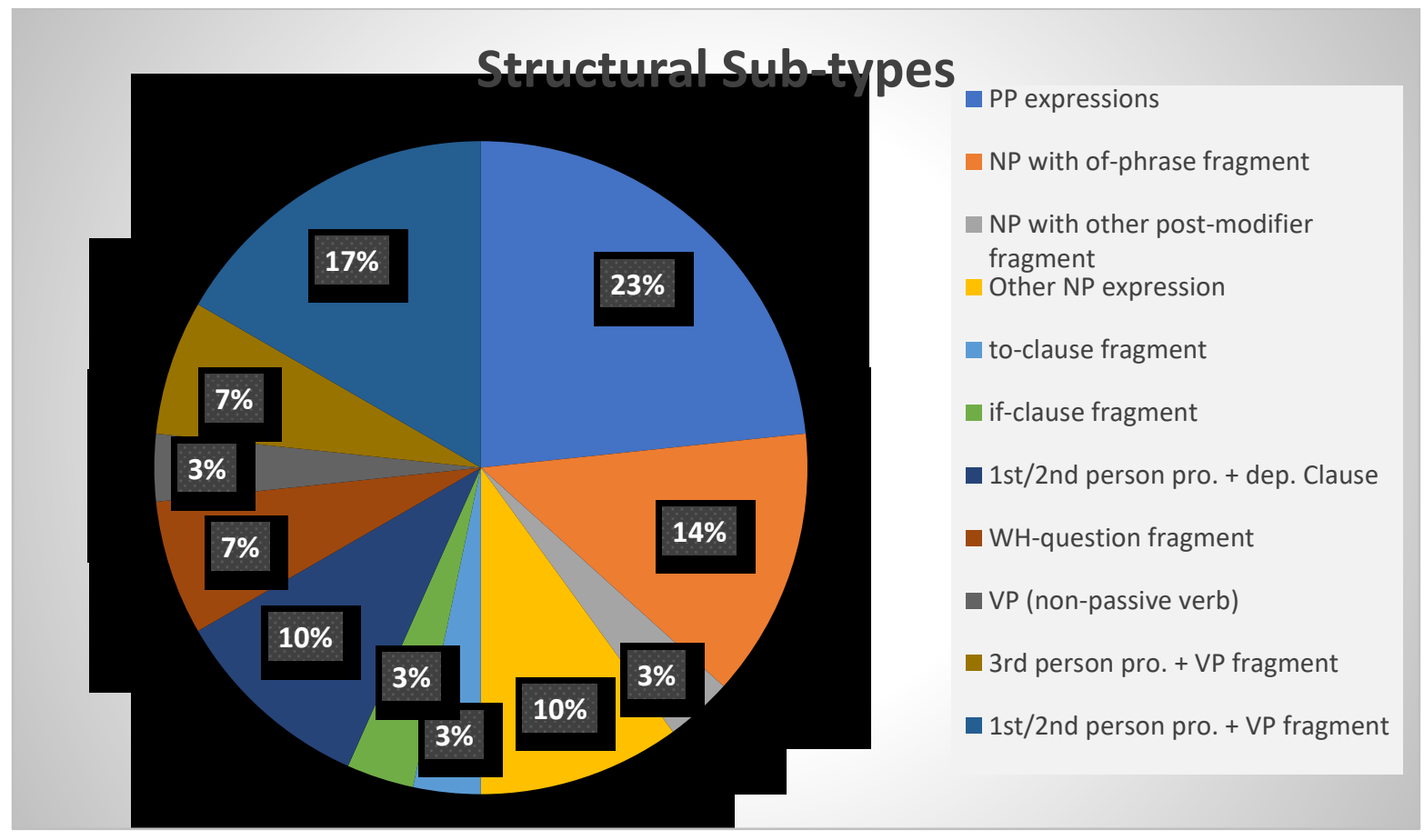


Figure 3.5 Structural sub-types of lexical bundles in the top 30 entries.

These findings are a sharp contrast to those of Biber et al. (2004), who found that in conversation, VP-based bundles were most frequent by a substantial margin, followed by dependent clause bundles, with NP/PP based bundles a very distant third. The present list seems to show a distribution more similar to what was observed in classroom teaching, in which VPbased bundles were again the most frequent type, but where NP/PP and dependent clause bundles were nearly as frequent (Biber et al., 2004). This may indicate that, at least in terms of the lexical bundles used, interactive academic discourse may share more similarities with classroom teaching than with ordinary conversation. This is not altogether unexpected; as Biber argues, "even student study groups are to a large extent controlled by instructors, who have helped to establish the parameters of discussion in their earlier classroom teaching" (2006, p. 119). It is not unreasonable, therefore, for there to be similarities between classroom teaching and student-centered groups. It is important to note that some of the speech encounters in the MSIC were led or facilitated by a graduate student instructor, which might have had some impact on the bundles found in these events. However, it is more likely that the similarities are simply the result of the topic areas being discussed, and their relation to the topics discussed within the lectures themselves.

A number of subcategories are not present at all in the top 30 items, such as comparative expressions and yes-no question fragments, which one might expect to be common in spoken discourse. Again, this may be indicative of the differences between conversation and academic conversation. 


\section{Chapter 4: Discussion}

This chapter will present a discussion of the results of this research. First, the potential implications of these findings for the teaching of English as a Second language will be discussed. This will be followed by a brief discussion of the limitations of this research, and then by a conclusion which will attempt to summarize and give an overall picture of the study.

\subsection{Potential Pedagogical Implications of the MSIC Bundles List}

\subsubsection{Previous Lists of Formulaic Sequences}

The frequent presence of lexical bundles in interactive contexts in academia has some potential implications for the instruction of English as a second language, particularly in the context of English for Academic Purposes (EAP). Studies have already shown the effectiveness of explicit teaching of formulaic sequences for student writers in an EAP context (Chen \& Baker, 2010; AlHassan \& Wood, 2015). It seems that if student writers wish to succeed academically, they must be able to recognize and employ the most frequent formulaic sequences found in the academic genre. This is likely to be equally true for spoken language. While EAP is frequently more focused on the written aspects of academic life, it is important to understand that many university students need to participate in academic discussions, and non-native speakers are no exception. If lexical bundles common in spoken language are presented in EAP classes, it is possible that learners will be better equipped to cope with participatory academic speech events.

Several attempts have previously been made to determine which sequences could or should be used in the instruction of formulaic language. Boers and Lindstromberg (2009) identified two main criteria in selecting "chunks" for use in the academic context: utility, that is, sequences which are useful for a particular group of students based on their proficiency and the needs of their area of study; and teachability, which refers to the ease with which these chunks can be memorized. While these are useful criteria, it is particularly difficult to determine the 
teachability of a particular formulaic sequence. Boers and Lindstromberg's definition of teachability is largely concerned with memory; they state that sequences which "can be made more memorable in an efficient way we consider highly teachable" (2009, p. 69). However, this assumes that memorizing a sequence is equivalent to learning it. While the issue of teachability is highly debatable, the principle of utility is nevertheless a sound method of determining which bundles to teach.

Several lists of potential formulaic sequences have been created for the purposes of use in teaching English as a Second language, according to various criteria; most of these have used the criteria of utility in some way. Perhaps most notably in the academic genre, Simpson-Vlach and Ellis (2010) compiled an Academic Formulas List (AFL) from a corpus of 2.1 million words of academic speech and writing, which they then compared to non-academic corpora in order to determine which sequences were truly academic. Meanwhile, several less academic-focused lists were also created. Shin and Nation (2008) created a list of the most frequent collocations in spoken English, based on data from the British National Corpus. It is important to clarify that this list, however, consists of sequences which are two words or more in length - meaning, of course, that many of the items in the list are only two words in length. Martinez and Schmitt (2012) created the Phrasal Expressions (PHRASE) List, which consisted of non-transparent multi-word expressions and was intended as "a guide for language learners and educators to include formulaic sequences in their learning and teaching, particularly for receptive purposes" (p. 302). As with Shin and Nation's list, the items in the PHRASE List can be as short as two words in length. Each of these lists is, in its own way, useful for determining the most frequent sequences in spoken English, and each is in some way concerned with the principle of utility. 
Likewise, in compiling the MSIC Bundles List, effort has been made to focus on utility. This principle has been approached in three ways: first, via the characteristic selection criteria of lexical bundles (i.e. frequency and range); second, through elimination of bundles that are unsuitable for teaching; and finally, through analysis of function and structural characteristics. The main way in which the MSIC Bundles List differs from previous lists is that it focuses on the academic genre, but consists of expressions that are not necessarily found in textbooks and journal articles. It is targeted rather at interactive spoken contexts. It is possible that this list has some utility for non-academic contexts as well; further research using spoken corpora might well show that the bundles found in this list occur with similar frequency in non-academic conversation. Biber (2006) asserts that classroom lectures often contain linguistic features that are similar to those found in conversation; it is not unlikely, then, that study groups may also share some features with conversational registers. The two do not overlap perfectly, but there may be some utility in this list for conversation as well.

The potential usefulness of formulaic sequences (including lexical bundles) for second language speakers lies in the ability of these sequences to improve fluency and pragmatic competence. Boers et al. (2006) hypothesized that mastery of formulaic language could have three major benefits for second language speakers: first, that they would be perceived as more fluent; second, that they would possess a greater range of expression; and finally, that they would be perceived as more accurate speakers. Their study found that second language speakers who received instruction in formulaic sequences (specifically, awareness-raising activities) were perceived as having greater oral proficiency by EFL teacher judges, particularly in terms of fluency and range of expression (Boers et al., 2006). While the study did not indicate that the 
participants' accuracy had necessarily improved, these are still important findings which speak to the benefits of formulaic language instruction in a second language learning context.

In sum, several lists of formulaic sequences for use in university contexts exist, based on different criteria and having used different methods of compilation. Each list has strengths and weaknesses; it is up to the instructor to select the list which best fits the needs of his or her students.

\subsubsection{Teaching Lexical Bundles and other Formulaic Sequences}

Despite the numerous efforts of researchers to select suitable formulaic sequences for EAP, a number of significant challenges remain. EAP is a very diverse teaching context, having students from a multitude of different cultural, linguistic and educational backgrounds, all of whom have their own academic goals, strengths and weaknesses; these difficulties are compounded by the wide variety of levels, materials and purposes of EAP courses at different institutions (Coxhead, 2008). Taking into account these vast differences, it is very difficult, if not impossible, to create a "one-size-fits-all" solution to teaching formulaic sequences. As a result, it is necessary to select sequences that are applicable to a narrower context, as in the present study, which has focused on spoken items in the humanities and social sciences.

Though lexical bundles (and other formulaic sequences) are ubiquitous in both conversation and writing, research seems to indicate that their acquisition and use by learners is not at all easy (Wood, 2015). Cortes (2004) studied the use of formulaic language by students in biology and history, and found that not only did they seldom use the most common formulaic sequences, but that they also used them to accomplish different pragmatic goals. The reason for this is not entirely clear, but it is possible that a lack of instruction specifically targeted at formulaic sequences, or an overall unfamiliarity with the functions of these sequences, may be the culprit. 
Two significant questions as to the implementation of lexical bundles or other formulaic sequences in EAP teaching are how the material should be presented and how the learning process should work. Given the importance of these sequences to language development and proficiency, it is important that instructors of English as a second language (particularly in academia) are prepared to give students the necessary opportunities for feedback and practice in this area. Unfortunately, despite the growing amount of research on formulaic language, there have as yet been few efforts to turn this knowledge into effective teaching methodologies (Wood, 2015) and there has certainly not yet emerged a consensus as to the most effective methodology to use in teaching formulaic sequences.

Some previous studies have suggested different methods for teaching formulaic sequences. Nattinger and DeCarrico (1992), in their study of lexical phrases, laid the foundations for some general principles of formulaic language teaching. As their focus is on production, (through conversation) they suggest that lexical items are best learned through a two-step approach: pattern drills, to improve the learners' fluency, followed by a slot-and-filler approach to variation. In other words, they suggest an almost audiolingual approach in which learners are taught lexical phrases as frames to be modified as needed. This method is perhaps closest to a "traditional" approach to second language pedagogy.

Lewis (1997) proposed a "lexical approach" to the teaching of what he referred to as "chunks", based on awareness-raising, rather than formal teaching. The justification for this approach came from the sheer number of potentially useful sequences that would need to be taught in order to equip a learner with sufficient proficiency. Time constraints would make the formal teaching of hundreds or thousands of vocabulary items impossible; therefore under the lexical approach less time would be given to individual words and still less to grammar, and 
instead this time would be given to lexical items which carry the referential meanings found in writing, and those that bear pragmatic meanings in speech (Lewis, 1997). This approach would necessarily create a classroom largely focused on receptive activities, as it would be up to the teacher to present the lexical items to be taught. However, Lewis argues that productive practices would still occur, and that "the exercise types [would] resemble those of standard vocabulary or grammar teaching, although the linguistic focus is different" (1997, p. 261).

However, Wray (2000), in a criticism of the approaches of Lewis and Nattinger and DeCarrico, argues that as formulaic sequences are not meant to be analyzed based on their component parts due to being stored as wholes in memory, it is counterproductive to encourage learners to analyze these sequences. Willis (1990) makes the counter-argument that second language learners do not process language in the same way as native speakers do, and therefore that analysis of formulaic sequences by learners is acceptable and even desirable. This is a question which has significant implications for teaching: do second language learners process formulaic sequences in the same way that native speakers do? This debate may not be settled in the near future; regardless, it is necessary for instructors to choose which side to agree with and subsequently to select a suitable teaching method.

On the more native-like side of the debate, there is the method of simple memorization, as examined by Boers and Lindstromberg (2009), which is a legitimate way in which formulaic sequences may be learned. Perhaps the simplest method would be to simply present learners with a list of items such as the AFL, or the list in the present study, and ask them to memorize said items. Boers and Lindstromberg, however, suggest that the most frequent items in a language are not necessarily the ideal choices for teaching; rather they define a "priority zone" (2009, pp. 6264) of items which are of moderate frequency and greater fixedness. The justification for this is 
twofold: first, learning only the most frequent sequences will not allow learners to move beyond a beginner level of proficiency; second, it is the more fixed expressions which will allow for more fluent production and with less chance of error (Boers \& Lindstromberg, 2009). It seems likely, however, that this applies mainly to lexical items used in conversational registers, rather than those specific to academia.

The effectiveness of rote memorization on learners' use of formulaic sequences was examined by Wray and Fitzpatrick (2008), who studied the use of formulaic sequences by nonnative speakers who had memorized and practiced native-like sentences which had been created specifically for them according to their learning goals and needs. Their study profiled the ways in which the participants' use of these sentences deviated from their original forms; deviations were considered acceptable provided they were similar to those that a native speaker might make. The results of the study indicated that there was an improvement in the learners' confidence in their ability to use native-like sequences (Wray \& Fitzpatrick, 2008). It may be that memorization is an effective way of increasing proficiency with formulaic sequences.

Awareness-raising is another potential method of teaching formulaic language, specifically the enhancement of texts including formulaic sequences. The enormous size of a lexicon prevents mastery from easily being attained through deliberate teaching and study alone (Nation, 2013). It seems likely, therefore, that some degree of learning will be achieved "as a byproduct, so to speak, of activities where the learner engages first and foremost with communicative content" (Boers et al., 2017, pp.449-450). Some studies have examined the effectiveness of this method. In a study involving the teaching of German formulaic sequences, Peters (2012) found that typographic enhancement (specifically, underlining and using bold typeface) had a beneficial effect on the participants' recall of the target sequences. Boers et al. 
(2017) also investigated typographic enhancement of formulaic language, in this case underlined in adapted texts. They found that the participants remembered the enhanced items somewhat more successfully than the unenhanced; they suggest that formulaic language lends itself well to this technique (Boers et al., 2017). While the effects of text enhancement may be modest, its relative simplicity means that it can easily be employed alongside other teaching methods.

Webb, Newton and Chang (2013) conducted a study on the incidental learning of target collocations in a graded reader which learners read and listened to simultaneously. They found that encounters with a target collocation in a text led to higher post-test scores, and that an increased number of encounters led to larger gains. The authors concluded that including collocations (particularly in large numbers) in graded reading might obviate the need for explicit teaching (Webb, Newton \& Chang, 2013). Using this method, target sequences would be chosen, presumably from one of the many lists of formulaic sequences useful for the chosen context, such as the AFL, PHRASE List, or the list in the present study. These sequences would then be added to input such as graded readers - "flooding" the input with the target language (Wood, 2015). This technique could, of course, be combined with text enhancement, potentially leading to still greater gains in acquisition; research on the effectiveness of combining these two techniques would need to be done.

Some pedagogical intervention studies on the success of teaching of formulaic sequences, including lexical bundles, have returned mixed results. Jones and Haywood (2004) conducted a study on recurrent word combinations, instructing EAP students in these expressions over a 10week period. The results indicated that the learners did not show major gains in the acquisition of these sequences, but did seem more motivated and more likely to use these expressions. Cortes (2006) found no increase in use of lexical bundles in student writing after a series of micro- 
lessons introducing the use of bundles; this study did, however, reveal that the students had an increased interest and awareness in lexical bundles following the intervention. A longitudinal study by Crossley and Salsbury (2011) found that L2 learners' ability to produce lexical bundles accurately increased over time.

The implication of these studies appears to be that there is as yet no consensus on the "correct" method for teaching lexical bundles or other formulaic sequences, nor is there any single methodology that is generally considered superior to the others. However, the small number and relatively small size of existing studies may indicate that more research needs to be done in order to discover more effective methods of teaching these sequences. It is possible that a combination of techniques may be the most effective method of ensuring that learners have the best chance of acquiring formulaic language.

As with other lists of formulaic language, the MSIC Bundles list has been designed with a view to not only providing insight into language use, but also for use as a pedagogical tool. The list has the potential to be used with several different techniques, such as memorization, text enhancement or input flooding, or through explicit teaching. Ultimately, the particular teaching method with which the list is to be combined in the classroom is left to the instructor's discretion.

\subsection{Conclusions}

\subsubsection{Limitations of the present study}

Despite the interesting results found in the present study, there are limitations that must be acknowledged. At approximately 230,000 words, the corpus that was used for this study is not particularly large; furthermore, it is limited to speech events which occurred at a single geographical location over a relatively short period of time. It could also be argued that as the MICASE corpus was compiled nearly twenty years ago, the language used may no longer 
accurately represent current use. The vast majority of the participants were native speakers of English; while for some this may constitute an ideal "model" for interactive academic speech, in reality it does not reflect the often-varied makeup of language backgrounds found in a university setting.

A larger, more in-depth study of interactive academic speech encounters might provide more data; this would, however, require the compilation of a corpus of such encounters. Ideally, this corpus would consist of transcripts of seminars and study groups from a number of universities, with a wide variety of topics being discussed. It would also be advantageous to future research if corpora of both native and non-native speakers in these speech encounters could be compiled, perhaps even separately, as this would allow for the comparison of lexical bundle use among both groups. Of course, no such corpus currently exists, making MICASE the best option for the present study.

While effort has been made to remove human judgment from the research process in this study, it was impossible to eliminate it entirely. There is a possibility that potentially useful lexical bundles have been excluded from the final list, or that unnecessary items have been included, simply because the decision to include or exclude items was based largely on the researcher's judgment. Likewise, the categorization of the bundles in the list, both in terms of function and structural characteristics, is based on human interpretation and therefore may not be entirely free from bias and/or subjectivity. Indeed, each step of the process following the initial application of range and frequency criteria has been subjective. This may be an unavoidable problem in this type of research, however, as it does not appear to be currently possible for a computer program to make reliable judgments regarding the usefulness or appropriacy of lexical 
bundles to a given academic context. Until human judgment can be removed entirely from the process, it will remain an unavoidable limitation of studies of this type.

The best method of coping with this problem and increasing reliability would be to employ multiple researchers in order to evaluate the utility and appropriacy of selected bundles, and to more reliably categorize them according to function and structure. However, due to various circumstances, this was not possible in the current study.

\subsubsection{Conclusion}

The present study has made an effort to take lexical bundle research into a less-explored area by examining lexical bundle use in interactive academic contexts. Non-native speakers of English in a university environment are usually given instruction (through EAP courses) in how to survive at university; however, these courses often focus on the language of reading, writing, and in some cases lectures. This focus comes at the expense of other speech events such as seminars and study groups, in which students are frequently required to participate. The language of lectures and textbooks may not adequately prepare these learners to participate in more interactive speech encounters, which means that they may be reluctant to share their opinions and ideas.

There is great potential for future research in this area. Deeper investigations into academic corpora may reveal other interesting patterns to the lexical bundles which appear in interactive speech, as well as the functions and structural characteristics of these bundles. Comparative studies showing the differences in lexical bundle use between genres such as the humanities and hard sciences might help to produce teaching materials that are more contextspecific. Additionally, studies involving pedagogical intervention could help to show the effectiveness of these materials on second language learners' use of academic bundles. 
Equipping second language learners with the necessary tools to participate in interactive academic speech events requires knowledge of the speech - including lexical bundles - that these events typically use. With a list of target items, based on real-world interactive speech events, it may be easier for instructors to help prepare their students to fully participate in these events. Equipped with this knowledge and with the confidence that they possess a repertoire of appropriate language, these learners' experiences will be richer for it. 


\section{References}

AlHassan, L., \& Wood, D. (2015). The effectiveness of focused instruction of formulaic sequences in augmenting L2 learners' academic writing skills: A quantitative research study. Journal of English for Academic Purposes, 17, 51-62.

Altenberg, B. (1998). On the phraseology of spoken English: the evidence of recurrent word combinations. In A.P. Cowie (Ed.), Phraseology: Theory, analysis and application (pp. 101-122). Oxford: Clarendon Press.

Appel, R.F. (2011). Lexical bundles in university EAP exam writing samples: CAEL test essays (Master's thesis). Retrieved from

http://search.proquest.com.proxy.library.carleton.ca/docview/995341942?pqorigsite $=$ summon

Ari, O. (2006). Review of three software programs designed to identify lexical bundles. Language Learning \& Technology, 10 (1), 30-37.

Bardovi-Harlig, K. (2012). Formulas, routines, and conventional expressions in pragmatics research. Annual Review of Applied Linguistics, 32, 206.

Biber, D. (2006a). University language: A corpus-based study of spoken and written registers. Amsterdam; Philadelphia: John Benjamins.

Biber, D. (2006b). Stance in spoken and written university registers. Journal of English for Academic Purposes, 5(2), 97-116.

Biber, D., \& Barbieri, F. (2007). Lexical bundles in university spoken and written registers. English for Specific Purposes, 26(3), 263-286.

Biber, D., Conrad, S., \& Cortes, V. (2003). Lexical bundles in speech and writing: an initial taxonomy. In A. Wilson, P. Rayson, \& T. McEnery (Eds.), Corpus linguistics by the Lune: a festschrift for Geoffrey Leech (pp. 71-92). Frankfurt/Main: Peter Lang.

Biber, D., Conrad, S., \& Cortes, V. (2004). If you look at... lexical bundles in academic lectures and textbooks. Applied Linguistics, 25, 371-405.

Biber, D., Johansson, S., Leech, G, Conrad, S., \& Finnegan, E. (1999). Longman grammar of spoken and written English. Essex: Pearson Education Limited.

Boers, F., \& Lindstromberg, S. (2009). Optimizing a lexical approach to instructed second language acquisition. Basingstoke: Palgrave Macmillan.

Boers, F., Eyckmans, J., Kappel, J., Stengers, H., \& Demecheleer, M. (2006). Formulaic sequences and perceived oral proficiency: Putting a lexical approach to the test. Language Teaching Research, 10(3), 245-261.

Boers, F., Demecheleer, M., He, L., Deconinck, J., Stengers, H., and Eyckmans, J. (2017). Typographic enhancement of multiword units in second language text. International Journal of Applied Linguistics, 27, 448-469.

Bolinger, D. (1976). Meaning and memory. Forum Linguisticum 1, 1-14.

Chen, L. (2010). An investigation of lexical bundles in ESP textbooks and electrical engineering introductory textbooks. In D. Wood (Ed.), Perspectives on formulaic language: Acquisition and communication, 107-125.

Cheng, S.W. (2010). A corpus-based approach to the study of speech act of thanking. Concentric: Studies in Linguistics, 36(2), 257-274.

Conrad, S., \& Biber, D. (2004). The frequency and use of lexical bundles in conversation and academic prose. Lexicographica, 20, 56-71. 
Cortes, V. (2006). Teaching lexical bundles in the disciplines: An example from a writing intensive history class. Linguistics and Education, 17(4), 391-406.

Coxhead, A., \& Byrd, P. (2007). Preparing writing teachers to teach the vocabulary and grammar of academic prose. Journal of Second Language Writing, 16(3), 129-147.

Crossley, S., \& Salsbury, T. L. (2011). The development of lexical bundle accuracy and production in English second language speakers. International Review of Applied Linguistics in Language Teaching, 49(1), 1-26.

Ellis, N. C. (2012). Formulaic language and second language acquisition: Zips and the phrasal teddy bear. Annual Review of Applied Linguistics, 32, 17-44.

Ellis, N. C., Simpson-Vlach, R., \& Maynard, C. (2008). Formulaic language in native and second language speakers: Psycholinguistics, corpus linguistics, and TESOL. TESOL Quarterly, 42(3), 375-396.

Flowerdew, J. (Ed.). (1994). Academic Listening: Research Perspectives. New York: Cambridge University Press.

Furneaux, C., Locke, C., Robinson, P., and Tonkyn, A. (1991). Talking heads and shifting bottoms: the ethnography of academic seminars. In P. Adams, B. Heaton, and P. Howarth (Eds.), Sociocultural issues in English for academic purposes (pp. 75-87). London: Modern English Publications in Association with the British Council.

Grant, L. E. (2005). Frequency of core idioms in the British national corpus (BNC). International Journal of Corpus Linguistics, 10(4), 429-451.

Hyland, K. (2008). As can be seen: Lexical bundles and disciplinary variation. English for Specific Purposes, 27(1), 4-21.

Jones, M., \& Haywood, S. (2004). Facilitating the acquisition of formulaic sequences. In N. Schmitt (Ed.), Formulaic sequences (pp. 269-292). Amsterdam/Philadelphia: John Benjamins.

Martinez, R., \& Schmitt, N. (2012). A phrasal expressions list. Applied Linguistics, 33(3), pp. 299-320.

Myles, F., Mitchell, R., \& Hooper, J. (1999). Interrogative chunks in French L2: A basis for creative construction? Studies in Second Language Acquisition, 21(1), 49.

Nation, I. S. P. (2013). Learning vocabulary in another language. Cambridge: Cambridge University Press.

Nesi, H., \& Basturkmen, H. (2006). Lexical bundles and discourse signaling in academic lectures. International Journal of Corpus Linguistics, 11, 283-304.

Pawley, A. \& Syder, F.H. (1983). Two puzzles for linguistic theory: Nativelike selection and nativelike fluency. In J. C. Richards \& R. W. Schmidt (eds.), Language and Communication. New York: Longman, 191-226.

Peters, E. (2012). Learning German formulaic sequences: The effect of two attention-drawing techniques. The Language Learning Journal, 40(1), 65-79.

Poos, D., \& Simpson, R. (2002). Cross-disciplinary comparisons of hedging: some findings from the Michigan Corpus of Academic Spoken English. In R. Reppen, S. Fitzmaurice, \& D. Biber (Eds.), Using corpora to explore linguistic variation (pp. 3-21). Philadelphia: John Benjamins.

Shin, D., \& Nation, P. (2008). Beyond single words: The most frequent collocations in spoken English. ELT Journal, 62(4), 339-348. 
Simpson, R. (2004). Stylistic features of academic speech: The role of formulaic expressions. In U. Connor, \& T.A. Upton, (Eds.), Discourse in the professions: Perspectives from corpus linguistics. Philadelphia: J. Benjamins.

Simpson-Vlach, R., \& Ellis, N.C. (2010). An academic formulas list: New methods in phraseology research. Applied Linguistics, 31(4), 487-512.

Simpson-Vlach, R., \& Leicher, S. (2006). The MICASE Handbook. Ann Arbor: The University of Michigan Press.

Swales, J. M. (2001). Metatalk in American academic talk. Journal of English linguistics, 29(1), 34-54.

Taguchi, N. (2011). Teaching pragmatics: Trends and issues. Annual Review of Applied Linguistics, 31, pp, 289-310.

Tracy, K. (1997). The Colloquium: Dilemmas of Academic Discourse. Norwood, NJ: Ablex.

Vermeer, A. (2000). Coming to grips with lexical richness in spontaneous speech data. Language Testing, 17(1), 65-83.

Webb, S., Newton, J. and Chang, A. (2013), Incidental learning of collocation. Language Learning, 63, 91-120.

Weinert, R. (1995). The role of formulaic language in second language acquisition: A review. Applied Linguistics, 16(2), 180-205.

Willis, D. (1990). The lexical syllabus. London: Harper Collins.

Wood, D. (2002). Formulaic language in acquisition and production: Implications for teaching. TESL Canada Journal, 20(1), 1-15.

Wood, D. (2009). Effects of focused instruction of formulaic sequences on fluent expression in second language narratives: A case study. The Canadian Journal of Applied Linguistics, $12(1), 39$.

Wood, D. (2015). Fundamentals of formulaic language: An introduction. London: Bloomsbury.

Wray, A. (2000). Formulaic sequences in second language teaching: Principle and practice. Applied Linguistics, 21(4), 463-489. 


\section{Appendix 1: MSIC Lexical Bundles List}

\begin{tabular}{|c|c|c|c|c|c|c|}
\hline Rank & Sequence & Freq. & Texts & $\%$ of texts & Type & Sub-type \\
\hline 1 & I DON'T KNOW IF & 79 & 13 & 92.86 & stance & epistemic stance (personal) \\
\hline 2 & AT THE SAME TIME & 36 & 12 & 85.71 & referential & time reference \\
\hline 3 & OR SOMETHING LIKE THAT & 33 & 9 & 64.29 & referential & imprecision \\
\hline 4 & AT THE END OF & 30 & 7 & 50.00 & referential & multi-functional reference \\
\hline 5 & THE END OF THE & 28 & 7 & 50.00 & referential & multi-functional reference \\
\hline 6 & I DON'T KNOW WHAT & 27 & 13 & 92.86 & stance & epistemic stance (personal) \\
\hline 7 & SO I DON'T KNOW & 25 & 8 & 57.14 & stance & epistemic stance (personal) \\
\hline 8 & WHAT DO YOU THINK & 24 & 8 & 57.14 & discourse & topic introduction/focus \\
\hline 9 & A LITTLE BIT ABOUT & 22 & 8 & 57.14 & discourse & topic introduction/focus \\
\hline 10 & A LOT OF THE & 22 & 5 & 35.71 & referential & quantity specification \\
\hline 11 & I THINK IT WAS & 21 & 10 & 71.43 & stance & epistemic stance (personal) \\
\hline 12 & KNOW WHAT I MEAN & 20 & 9 & 64.29 & discourse & topic elaboration/clarification \\
\hline 13 & IF YOU LOOK AT & 17 & 8 & 57.14 & discourse & topic introduction/focus \\
\hline 14 & WHAT DO YOU MEAN & 17 & 7 & 50.00 & discourse & topic elaboration/clarification \\
\hline 15 & I DON'T KNOW HOW & 16 & 9 & 64.29 & stance & epistemic stance (personal) \\
\hline 16 & IT SEEMS TO ME & 16 & 7 & 50.00 & stance & epistemic stance (personal) \\
\hline 17 & YOU DON'T HAVE TO & 14 & 8 & 57.14 & stance & $\begin{array}{l}\text { attitudinal/modality stance } \\
\text { (obligation/directive - personal) }\end{array}$ \\
\hline 18 & I THOUGHT IT WAS & 13 & 9 & 64.29 & stance & epistemic stance (personal) \\
\hline 19 & TO BE ABLE TO & 13 & 9 & 64.29 & stance & ability (impersonal) \\
\hline 20 & ON THE OTHER HAND & 12 & 7 & 50.00 & discourse & topic elaboration/clarification \\
\hline 21 & IN THE CASE OF & 12 & 6 & 42.86 & referential & $\begin{array}{l}\text { specification of attributes } \\
\text { (intangible) }\end{array}$ \\
\hline 22 & ON THE ONE HAND & 12 & 5 & 35.71 & discourse & topic elaboration/clarification \\
\hline 23 & A CERTAIN AMOUNT OF & 10 & 6 & 42.86 & referential & quantity specification \\
\hline 24 & IN THE SAME WAY & 10 & 5 & 35.71 & referential & $\begin{array}{l}\text { specification of attributes } \\
\text { (intangible) }\end{array}$ \\
\hline 25 & IT SEEMS TO BE & 10 & 4 & 28.57 & stance & epistemic stance (impersonal) \\
\hline 26 & IN THE SENSE THAT & 10 & 3 & 21.43 & referential & $\begin{array}{l}\text { specification of attributes } \\
\text { (intangible) }\end{array}$ \\
\hline 27 & ONE OF THE THINGS & 9 & 6 & 42.86 & referential & identification/focus \\
\hline 28 & WHEN YOU TALK ABOUT & 9 & 6 & 42.86 & referential & time reference \\
\hline 29 & A LITTLE BIT OF & 9 & 4 & 28.57 & referential & quantity specification \\
\hline 30 & THAT'S A GOOD POINT & 9 & 4 & 28.57 & stance & epistemic stance (personal) \\
\hline 31 & WHAT IT MEANS TO & 9 & 4 & 28.57 & referential & time reference \\
\hline 32 & FOR THE SAKE OF & 9 & 3 & 21.43 & referential & $\begin{array}{l}\text { specification of attributes } \\
\text { (intangible) }\end{array}$ \\
\hline 33 & ALL OF A SUDDEN & 8 & 7 & 50.00 & referential & time reference \\
\hline 34 & I HAVE A QUESTION & 8 & 7 & 50.00 & discourse & topic elaboration/clarification \\
\hline 35 & HAS TO DO WITH & 8 & 6 & 42.86 & referential & $\begin{array}{l}\text { specification of attributes } \\
\text { (intangible) }\end{array}$ \\
\hline 36 & I HAVE NO IDEA & 8 & 6 & 42.86 & stance & epistemic stance (personal) \\
\hline
\end{tabular}




\begin{tabular}{|c|c|c|c|c|c|c|}
\hline 37 & HOW DO YOU KNOW & 8 & 5 & 35.71 & discourse & topic elaboration/clarification \\
\hline 38 & THE FACT THAT THERE & 7 & 5 & 35.71 & referential & $\begin{array}{l}\text { specification of attributes } \\
\text { (intangible) }\end{array}$ \\
\hline 39 & ALL OF THESE THINGS & 7 & 4 & 28.57 & referential & identification/focus \\
\hline 40 & SEE WHAT I MEAN & 7 & 4 & 28.57 & discourse & topic elaboration/clarification \\
\hline 41 & THE SAME THING AS & 7 & 4 & 28.57 & referential & identification/focus \\
\hline 42 & WHAT DOES THAT MEAN & 7 & 4 & 28.57 & discourse & topic elaboration/clarification \\
\hline 43 & I DON'T KNOW WHETHER & 7 & 3 & 21.43 & stance & epistemic stance (personal) \\
\hline 44 & NOT THE SAME THING & 7 & 3 & 21.43 & referential & specification of attributes (intangible) \\
\hline 45 & THE WAY IN WHICH & 7 & 3 & 21.43 & referential & specification of attributes (intangible) \\
\hline 46 & IF YOU HAVE A & 6 & 6 & 42.86 & referential & $\begin{array}{l}\text { attitudinal/modality stance } \\
\text { (ability - personal) }\end{array}$ \\
\hline 47 & I'M NOT SURE IF & 6 & 6 & 42.86 & stance & epistemic stance (personal) \\
\hline 48 & THE BEST WAY TO & 6 & 6 & 42.86 & referential & identification/focus \\
\hline 49 & TO LOOK AT IT & 6 & 6 & 42.86 & referential & identification/focus \\
\hline 50 & A GOOD EXAMPLE OF & 6 & 5 & 35.71 & referential & identification/focus \\
\hline 51 & A LITTLE BIT MORE & 6 & 5 & 35.71 & referential & quantity specification \\
\hline 52 & IS SUPPOSED TO BE & 6 & 5 & 35.71 & stance & obligation/directive (impersonal) \\
\hline 53 & SEE WHAT YOU'RE SAYING & 6 & 5 & 35.71 & discourse & topic elaboration/clarification \\
\hline 54 & WHAT WAS GOING ON & 6 & 5 & 35.71 & referential & time reference \\
\hline 55 & YOU WERE TALKING ABOUT & 6 & 5 & 35.71 & discourse & topic elaboration/clarification \\
\hline 56 & AS LONG AS YOU & 6 & 4 & 28.57 & discourse & topic elaboration/clarification \\
\hline 57 & DOES THAT MAKE SENSE & 6 & 4 & 28.57 & discourse & topic elaboration/clarification \\
\hline 58 & DOESN'T HAVE TO BE & 6 & 4 & 28.57 & stance & $\begin{array}{l}\text { attitudinal/modality stance } \\
\text { (obligation/directive - impersonal) }\end{array}$ \\
\hline 59 & DOESN'T SEEM TO BE & 6 & 4 & 28.57 & stance & epistemic stance (impersonal) \\
\hline 60 & I JUST WANTED TO & 6 & 4 & 28.57 & stance & obligation/directive (personal) \\
\hline 61 & I WANT YOU TO & 6 & 4 & 28.57 & stance & obligation/directive (personal) \\
\hline 62 & IT'S THE SAME THING & 6 & 4 & 28.57 & stance & epistemic stance (impersonal) \\
\hline 63 & THAT'S A GOOD QUESTION & 6 & 4 & 28.57 & discourse & topic elaboration/clarification \\
\hline 64 & A PARTICULAR KIND OF & 6 & 3 & 21.43 & referential & specification of attributes (intangible) \\
\hline 65 & HAVE TO DO WITH & 6 & 3 & 21.43 & discourse & topic elaboration/clarification \\
\hline 66 & WHEN YOU LOOK AT & 6 & 3 & 21.43 & discourse & topic introduction/focus \\
\hline 67 & YOU CAN SAY THAT & 6 & 3 & 21.43 & discourse & topic elaboration/clarification \\
\hline 68 & YOU COULD SAY THAT & 6 & 3 & 21.43 & discourse & topic elaboration/clarification \\
\hline 69 & AND THEN YOU GET & 5 & 5 & 35.71 & discourse & topic elaboration/clarification \\
\hline 70 & THAT'S A GOOD IDEA & 5 & 5 & 35.71 & discourse & topic elaboration/clarification \\
\hline 71 & I WAS JUST WONDERING & 5 & 4 & 28.57 & discourse & topic elaboration/clarification \\
\hline 72 & IT'S KIND OF LIKE & 5 & 4 & 28.57 & discourse & topic elaboration/clarification \\
\hline 73 & MAY OR MAY NOT & 5 & 4 & 28.57 & stance & $\begin{array}{l}\text { attitudinal/modality stance } \\
\text { (intention/prediction) }\end{array}$ \\
\hline 74 & MIGHT BE ABLE TO & 5 & 4 & 28.57 & stance & $\begin{array}{l}\text { attitudinal/modality stance } \\
\text { (ability - personal) }\end{array}$ \\
\hline 75 & TAKE A LOOK AT & 5 & 4 & 28.57 & discourse & topic introduction/focus \\
\hline 76 & THE EXTENT TO WHICH & 5 & 3 & 21.43 & referential & specification of attributes \\
\hline
\end{tabular}




\begin{tabular}{|c|c|c|c|c|c|c|}
\hline & & & & & & (intangible) \\
\hline 77 & YOU COULD DO THAT & 5 & 3 & 21.43 & stance & $\begin{array}{l}\text { attitudinal/modality stance } \\
\text { (ability - personal) }\end{array}$ \\
\hline 78 & ALL THAT KIND OF & 4 & 4 & 28.57 & referential & $\begin{array}{l}\text { specification of attributes } \\
\text { (intangible) }\end{array}$ \\
\hline 79 & IF YOU THINK ABOUT & 4 & 4 & 28.57 & discourse & topic introduction/focus \\
\hline 80 & IT'S HARD TO TELL & 4 & 4 & 28.57 & stance & ability (impersonal) \\
\hline 81 & JUST TO MAKE SURE & 4 & 4 & 28.57 & discourse & topic elaboration/clarification \\
\hline 82 & THAT'S WHAT I THINK & 4 & 4 & 28.57 & stance & epistemic stance (personal) \\
\hline 83 & THAT'S WHAT I THOUGHT & 4 & 4 & 28.57 & discourse & topic elaboration/clarification \\
\hline 84 & WELL FIRST OF ALL & 4 & 4 & 28.57 & discourse & topic introduction/focus \\
\hline 85 & WHAT I THINK IS & 4 & 4 & 28.57 & stance & epistemic stance (personal) \\
\hline 86 & WHAT I WAS THINKING & 4 & 4 & 28.57 & discourse & topic introduction/focus \\
\hline 87 & ALL I'M SAYING IS & 4 & 3 & 21.43 & discourse & topic elaboration/clarification \\
\hline 88 & ARE YOU TRYING TO & 4 & 3 & 21.43 & discourse & topic elaboration/clarification \\
\hline 89 & DO YOU SEE WHAT & 4 & 3 & 21.43 & discourse & topic elaboration/clarification \\
\hline 90 & DOES THAT MEAN THAT & 4 & 3 & 21.43 & discourse & topic elaboration/clarification \\
\hline 91 & DON'T EVEN KNOW IF & 4 & 3 & 21.43 & stance & epistemic stance (personal) \\
\hline 92 & I DON'T AGREE WITH & 4 & 3 & 21.43 & stance & epistemic stance (personal) \\
\hline 93 & I GUESS IT IS & 4 & 3 & 21.43 & stance & epistemic stance (personal) \\
\hline 94 & I KNOW THAT IF & 4 & 3 & 21.43 & stance & epistemic stance (personal) \\
\hline 95 & IF ANY OF YOU & 4 & 3 & 21.43 & discourse & topic introduction/focus \\
\hline 96 & IF YOU THINK THAT & 4 & 3 & 21.43 & stance & epistemic stance (personal) \\
\hline 97 & I'M GONNA TRY TO & 4 & 3 & 21.43 & stance & $\begin{array}{l}\text { attitudinal/modality stance } \\
\text { (intention/prediction) }\end{array}$ \\
\hline 98 & I'M NOT WILLING TO & 4 & 3 & 21.43 & stance & $\begin{array}{l}\text { attitudinal/modality stance } \\
\text { (desire - personal) }\end{array}$ \\
\hline 99 & ON THE OTHER SIDE & 4 & 3 & 21.43 & referential & place reference \\
\hline 100 & OR ANYTHING LIKE THAT & 4 & 3 & 21.43 & referential & imprecision \\
\hline 101 & SOMETHING TO DO WITH & 4 & 3 & 21.43 & discourse & topic elaboration/clarification \\
\hline 102 & THAT DOESN'T MEAN THAT & 4 & 3 & 21.43 & discourse & topic elaboration/clarification \\
\hline 103 & THE FACT THAT IT'S & 4 & 3 & 21.43 & discourse & topic elaboration/clarification \\
\hline 104 & THE IDEA IS THAT & 4 & 3 & 21.43 & discourse & topic elaboration/clarification \\
\hline 105 & THE ROOT OF ALL & 4 & 3 & 21.43 & referential & identification/focus \\
\hline 106 & THE SAME WAY THAT & 4 & 3 & 21.43 & referential & identification/focus \\
\hline 107 & THE WHOLE IDEA OF & 4 & 3 & 21.43 & discourse & topic introduction/focus \\
\hline 108 & THIS IS THE ONE & 4 & 3 & 21.43 & referential & identification/focus \\
\hline 109 & THIS IS THE WAY & 4 & 3 & 21.43 & discourse & topic introduction/focus \\
\hline 110 & WAS SUPPOSED TO BE & 4 & 3 & 21.43 & discourse & topic elaboration/clarification \\
\hline 111 & WHEN WE TALK ABOUT & 4 & 3 & 21.43 & discourse & topic introduction/focus \\
\hline 112 & WHICH IS OF COURSE & 4 & 3 & 21.43 & discourse & topic elaboration/clarification \\
\hline 113 & WHY DO YOU THINK & 4 & 3 & 21.43 & discourse & topic elaboration/clarification \\
\hline 114 & WHY IS IT THAT & 4 & 3 & 21.43 & discourse & topic elaboration/clarification \\
\hline 115 & YOU LOOK AT THE & 4 & 3 & 21.43 & discourse & topic introduction/focus \\
\hline 116 & YOU TALK ABOUT THE & 4 & 3 & 21.43 & discourse & topic elaboration/clarification \\
\hline
\end{tabular}




\begin{tabular}{|c|c|c|c|c|c|c|}
\hline 117 & YOU'RE TALKING ABOUT THE & 4 & 3 & 21.43 & discourse & topic elaboration/clarification \\
\hline 118 & A COUPLE OF THINGS & 3 & 3 & 21.43 & referential & quantity specification \\
\hline 119 & A LOT OF STUFF & 3 & 3 & 21.43 & referential & quantity specification \\
\hline 120 & A LOT OF THINGS & 3 & 3 & 21.43 & referential & quantity specification \\
\hline 121 & A PART OF IT & 3 & 3 & 21.43 & referential & identification/focus \\
\hline 122 & ALL OVER THE PLACE & 3 & 3 & 21.43 & referential & place reference \\
\hline 123 & AND IN THAT SENSE & 3 & 3 & 21.43 & discourse & topic elaboration/clarification \\
\hline 124 & AND ONE OF THE & 3 & 3 & 21.43 & referential & identification/focus \\
\hline 125 & AND THE NOTION OF & 3 & 3 & 21.43 & discourse & topic elaboration/clarification \\
\hline 126 & AND THE OTHER ONE & 3 & 3 & 21.43 & discourse & topic elaboration/clarification \\
\hline 127 & AND THE THING IS & 3 & 3 & 21.43 & discourse & topic elaboration/clarification \\
\hline 128 & AND THEN OF COURSE & 3 & 3 & 21.43 & discourse & topic elaboration/clarification \\
\hline 129 & AS IF IT WERE & 3 & 3 & 21.43 & discourse & topic elaboration/clarification \\
\hline 130 & AS IF YOU WERE & 3 & 3 & 21.43 & discourse & topic elaboration/clarification \\
\hline 131 & AT LEAST FOR ME & 3 & 3 & 21.43 & discourse & topic elaboration/clarification \\
\hline 132 & BOTH OF THESE THINGS & 3 & 3 & 21.43 & referential & identification/focus \\
\hline 133 & DO WE NEED TO & 3 & 3 & 21.43 & stance & $\begin{array}{l}\text { attitudinal/modality stance } \\
\text { (obligation/directive - personal) }\end{array}$ \\
\hline 134 & DO YOU NEED TO & 3 & 3 & 21.43 & stance & $\begin{array}{l}\text { attitudinal/modality stance } \\
\text { (obligation/directive - personal) }\end{array}$ \\
\hline 135 & DON'T HAVE TO BE & 3 & 3 & 21.43 & stance & $\begin{array}{l}\text { attitudinal/modality stance } \\
\text { (obligation/directive - personal) }\end{array}$ \\
\hline 136 & DON'T HAVE TO GO & 3 & 3 & 21.43 & stance & $\begin{array}{l}\text { attitudinal/modality stance } \\
\text { (obligation/directive - personal) }\end{array}$ \\
\hline 137 & DON'T KNOW IF THIS & 3 & 3 & 21.43 & stance & epistemic stance (personal) \\
\hline 138 & DON'T KNOW IF YOU'VE & 3 & 3 & 21.43 & stance & epistemic stance (personal) \\
\hline 139 & DON'T KNOW WHAT IT & 3 & 3 & 21.43 & stance & epistemic stance (personal) \\
\hline 140 & DON'T KNOW WHAT THE & 3 & 3 & 21.43 & stance & epistemic stance (personal) \\
\hline 141 & DON'T KNOW WHAT YOU & 3 & 3 & 21.43 & stance & epistemic stance (personal) \\
\hline 142 & DON'T KNOW WHAT YOU'RE & 3 & 3 & 21.43 & stance & epistemic stance (personal) \\
\hline 143 & FIND IT DIFFICULT TO & 3 & 3 & 21.43 & stance & epistemic stance (personal) \\
\hline 144 & HAVE A PROBLEM WITH & 3 & 3 & 21.43 & stance & epistemic stance (personal) \\
\hline 145 & HAVE TO WORRY ABOUT & 3 & 3 & 21.43 & stance & $\begin{array}{l}\text { attitudinal/modality stance } \\
\text { (obligation/directive - personal) }\end{array}$ \\
\hline 146 & I CAN TELL YOU & 3 & 3 & 21.43 & stance & $\begin{array}{l}\text { attitudinal/modality stance } \\
\text { (ability - personal) }\end{array}$ \\
\hline 147 & I DIDN'T MEAN TO & 3 & 3 & 21.43 & stance & $\begin{array}{l}\text { attitudinal/modality stance } \\
\text { (intention/prediction -personal) }\end{array}$ \\
\hline 148 & I DO THINK THAT & 3 & 3 & 21.43 & stance & epistemic stance (personal) \\
\hline 149 & I DON'T HAVE IT & 3 & 3 & 21.43 & stance & ability (personal) \\
\hline 150 & I DON'T KNOW BECAUSE & 3 & 3 & 21.43 & stance & epistemic stance (personal) \\
\hline 151 & I DON'T KNOW CUZ & 3 & 3 & 21.43 & stance & epistemic stance (personal) \\
\hline 152 & I DON'T UNDERSTAND WHY & 3 & 3 & 21.43 & stance & epistemic stance (personal) \\
\hline 153 & I GUESS YOU COULD & 3 & 3 & 21.43 & stance & $\begin{array}{l}\text { attitudinal/modality stance } \\
\text { (ability - personal) }\end{array}$ \\
\hline 154 & I HAD A QUESTION & 3 & 3 & 21.43 & discourse & topic elaboration/clarification \\
\hline
\end{tabular}




\begin{tabular}{|c|c|c|c|c|c|c|}
\hline 155 & I MEAN IT SEEMS & 3 & 3 & 21.43 & discourse & topic elaboration/clarification \\
\hline 156 & I THINK THAT'S TRUE & 3 & 3 & 21.43 & stance & epistemic stance (personal) \\
\hline 157 & I THINK THERE'S A & 3 & 3 & 21.43 & stance & epistemic stance (personal) \\
\hline 158 & I THINK YOU HAVE & 3 & 3 & 21.43 & stance & epistemic stance (personal) \\
\hline 159 & I WANTED TO TALK & 3 & 3 & 21.43 & stance & $\begin{array}{l}\text { attitudinal/modality stance } \\
\text { (desire - personal) }\end{array}$ \\
\hline 160 & I WAS THINKING THAT & 3 & 3 & 21.43 & stance & epistemic stance (personal) \\
\hline 161 & I WILL TELL YOU & 3 & 3 & 21.43 & stance & $\begin{array}{l}\text { attitudinal/modality stance } \\
\text { (intention/prediction -personal) }\end{array}$ \\
\hline 162 & I'D LIKE TO KNOW & 3 & 3 & 21.43 & stance & $\begin{array}{l}\text { attitudinal/modality stance } \\
\text { (desire - personal) }\end{array}$ \\
\hline 163 & IF IT WOULD BE & 3 & 3 & 21.43 & discourse & topic elaboration/clarification \\
\hline 164 & IF YOU DON'T KNOW & 3 & 3 & 21.43 & discourse & topic elaboration/clarification \\
\hline 165 & IF YOU LOOKED AT & 3 & 3 & 21.43 & discourse & topic introduction/focus \\
\hline 166 & IF YOU WANT TO & 3 & 3 & 21.43 & stance & $\begin{array}{l}\text { attitudinal/modality stance } \\
\text { (desire - personal) }\end{array}$ \\
\hline 167 & IN THE NEXT PARAGRAPH & 3 & 3 & 21.43 & referential & text reference \\
\hline 168 & IS A GOOD THING & 3 & 3 & 21.43 & stance & epistemic stance (personal) \\
\hline 169 & IT'S GONNA BE HARD & 3 & 3 & 21.43 & stance & intention/prediction - impersonal \\
\hline 170 & NOTHING TO DO WITH & 3 & 3 & 21.43 & discourse & topic elaboration/clarification \\
\hline 171 & OH I DON'T KNOW & 3 & 3 & 21.43 & discourse & epistemic stance (personal) \\
\hline 172 & ONCE IN A WHILE & 3 & 3 & 21.43 & referential & time reference \\
\hline 173 & SAY SOMETHING ABOUT IT & 3 & 3 & 21.43 & discourse & topic elaboration/clarification \\
\hline 174 & SOME OF THE THINGS & 3 & 3 & 21.43 & referential & quantity specification \\
\hline 175 & TALK TO ME ABOUT & 3 & 3 & 21.43 & discourse & topic introduction/focus \\
\hline 176 & THAT HAS TO BE & 3 & 3 & 21.43 & discourse & topic elaboration/clarification \\
\hline 177 & THAT IT IS NOT & 3 & 3 & 21.43 & discourse & topic elaboration/clarification \\
\hline 178 & THAT KIND OF STUFF & 3 & 3 & 21.43 & referential & imprecision \\
\hline 179 & THAT WOULD BE GOOD & 3 & 3 & 21.43 & stance & $\begin{array}{l}\text { attitudinal/modality stance } \\
\text { (intention/prediction - impersonal) }\end{array}$ \\
\hline 180 & $\begin{array}{r}\text { THAT WOULD BE } \\
\text { INTERESTING }\end{array}$ & 3 & 3 & 21.43 & stance & $\begin{array}{l}\text { attitudinal/modality stance } \\
\text { (intention/prediction - impersonal) }\end{array}$ \\
\hline 181 & THE CASE OF THE & 3 & 3 & 21.43 & referential & $\begin{array}{l}\text { specification of attributes } \\
\text { (intangible) }\end{array}$ \\
\hline 182 & THE PROBLEM IS THAT & 3 & 3 & 21.43 & referential & identification/focus \\
\hline 183 & THE SENSE IN WHICH & 3 & 3 & 21.43 & referential & $\begin{array}{l}\text { specification of attributes } \\
\text { (intangible) }\end{array}$ \\
\hline
\end{tabular}

